\title{
Research Paper \\ The effectiveness of systemic-constructivist couple therapy (scet) on marital satisfaction and intimacy in older women-younger men marriages
}

Mojtaba Noorani ${ }^{1}$, Rezvanossadat Jazayeri $^{2}$ Maryam Fatehizadeh $^{\mathbf{3}}$
1. Ph.D Student in Family Counseling, Department of Counseling, University of Isfahan, Isfahan, Iran.
2. Assistant Professor, Department of Counseling, University of Isfahan, Isfahan, Iran.
3. Professor, Department of Counseling, University of Isfahan, Isfahan, Iran.

Citation: Noorani M, Jazayeri R, Fatehizadeh M. The effectiveness of systemic-constructivist couple therapy (scct) on marital satisfaction and intimacy in older women-younger men marriages. J of Psychological Science. 2021; 20(105): 1569-1586.
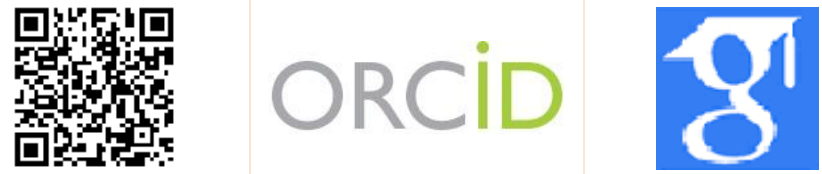

URL: https://psychologicalscience.ir/article-1-1065-fa.html

$\underline{10.52547 / J P S .20 .105 .1569}$

\section{A R T I C L E IN F O A B S T R A C T}

Keywords:

Older women-younger

men,

Marital Satisfacion,

Couple Intimacy,

Systemic Constructivist

Couple Therapy (SCCT)

Received: 02 Dec 2020

Accepted: 26 Dec 2020

Available: 22 Nov 2021
Background: Many studies have been conducted on marital satisfaction and intimacy of couples, but research on the effectiveness of systemic-constructivist couple therapy on intimacy and marital satisfaction, especially in Older women-younger men couples, has been neglected.

Aims: The aim of this study was to evaluate the effectiveness of Systemic-Constructivist Couple Therapy (SCCT) on Marital Satisfaction and Intimacy in Older women-younger men marriages.

Methods: This was a quasi-experimental study with a pre-test, post-test design, and follow-up with an experimental group and a control group. The population of this study consisted of all couples in older women-younger men marriages in Shiraz in 2019. Using the convenience sampling method, 30 couples were selected and randomly divided into experimental and control groups. In the pre-test stage, the short form of Enrich Marital Satisfaction Questionnaire (olson, 1998) and the couple intimacy (oulia, 2006) were given to both groups and then the systemic-constructivist couple therapy approach in 9 sessions per week Two hours, were performed for the experimental group. In order to analyze the data, repeated measures analysis of variance was used.

Results: The results of data analysis showed that systemic-constructive couple therapy on marital satisfaction and dimensions of emotional, intellectual, psychological, socio-recreational, communication, and general intimacy, had a significant effect $(P>0.05)$, while these interventions did not have a significant effect on physical, spiritual, and sexual intimacy.

Conclusion: Conclusions: From the obtained results, it can be concluded that systemic-constructivist couple therapy can be used to improve marital satisfaction and intimacy of couples.

* Corresponding Author: Rezvanossadat Jazayeri, Assistant Professor. Department of Counseling, University of Isfahan, Isfahan, Iran.

E-mail: r.jazayeri@edu.ui.ac.ir

Tel: (+98) 9177147761

2476-5740/ (C) 2021 The Authors. This is an open access article under the CC BY-NC-ND license

(https://creativecommons.org/licenses/by-nc/4.0/). 


\section{Extended Abstract}

\section{Introduction}

Marriage is one of the most important experiences in human life that helps him in the path of personal and social development (Markman, Rhodes, Stanley, Regan and Vuitton, 2010). Marital satisfaction is recognized as one of the basic concepts in examining the quality of a marriage. Zare and Safiari (2015) introduced marital satisfaction as a feeling of happiness and well-being of couples in marriage. Marital satisfaction means having pleasant feelings from different aspects of their marriage that directly affect the quality of life (Jafar Begloo, Momenian, and Khaki, 2019; Dado and Dabiri, 2009).

Another important concept in a marriage that is closely related to the concept of marital satisfaction is the intimacy of couples, which plays an important role in the dynamics of marriage and increasing marital satisfaction (Connery et al., 2016; Ferreira, Narciso, and Nova, 2013; Madnian, Seyed Mansour, Ben Omar 2012 and Patrick, and Beckenbach, 2009). Bagarozi (2013) described marital intimacy as empathizing and understanding other perspectives. a good marriage has a positive effect on the mental health of couples and increases the feeling of satisfaction in families and can also be useful in improving social relations (Yazdan Panah, Shahmoradi, Naghsh, 2018).

Age and age difference between couples is one of the essential criteria in choosing a spouse. Studies show that men tend to be a few years older than their spouses on average. This pattern is observed in almost all countries. A study by Jebraeili and Taheri (2014) showed that in Iran, most men prefer to be older than their wives (on average 2.85 years), and women prefer to be younger than their husbands (on average 4.45 years).

Although social developments in the field of marriage seem inevitable, a man's marriage to an older woman is an example of social changes that often confront couples with negative feedback from family, friends, and possibly marriage counselors. Erfanmanesh, Darvizeh, Khosravi, \& Hasanzadeh Tavakkoli, 2015; Colette, Banks, \& Arnold, 2001; noorani, jazayeri, fatehizade, 2020).
Statistics show that during the last 40 years, this type of marriage has quadrupled in Iran (erfanmanesh et al., 2015). Proulx et al., (2006) pointed to some dissatisfaction of women in these relationships, such as: looking old and the loss of beauty, reduced intimacy due to age differences that lead to disagreement in some aspects of married life such as power struggles, interests, and fertility.

One of the effective approaches in the field of couple therapy that can have a positive effect on increasing intimacy and marital satisfaction of couples is systemic-constructivist couple therapy. (Yousefzadeh, Farzad, Navabi Nejad and Nouranipour, 2017; Bidadian, Bahramizadeh, and Poursharifi, 2011; Mami and Safarnia, 1397; Masoudi Thani, Pakonia and Droudian, 2017). This approach is a therapeutic-experimental intervention based on a systemic-constructivist approach to the scientific study of dynamic and physiological factors in marriage (Reid, Dalton, Laudrot, Duel, \& Angwin, 2006). Systemic-constructivist therapy helps spouses to get closer to each other by providing pragmatic solutions and reduces their problems (Rajabi, Nobandagani, Amanollahi, 2006; Reid et al., 2006).

While many studies have examined the factors of marital satisfaction and intimacy among couples, no international training package was found for older women-younger men. It is the first time that such a program is being tested on Iranian couples. As such, the purpose of this research is to determine The effectiveness of SystemicConstructivist Couple Therapy (SCCT) on Marital Satisfaction and Intimacy in Older women-younger men marriages in Shiraz, Iran.

\section{Method}

The method of the present study is quasiexperimental and to do it, the pre-test-post-test and follow-up plan with the control group has been used. The statistical population of the study included all older women-young men couples in Shiraz 1398. Before participation in the group intervention, participants were contacted via telephone to be checked for suitability for this study. Of all the volunteers, a total of 30 couples were registered for the workshop. Couples were assigned randomly to an experimental and a control group (15 couples in each 


\section{Monthly Journal of Psychological Science}

group). The pre and post-intervention questionnaires included two scales. (a) Enrich Marital Satisfaction Questionnaire, and (b) the Couple Intimacy.

In this study, the short form of the Enrich Marital Satisfaction Questionnaire was used. A high score in this questionnaire is a sign of satisfaction and a low score is a sign of dissatisfaction with the marital relationship. Soleymanian (1993) reported the reliability of the questionnaire in short form by calculating the alpha coefficient, 0.95 .

To measure the degree of intimacy of couples, the couple intimacy questionnaire (oulia, Fatehizadeh, \& Bahrami, 2006) was used. This questionnaire has 85 questions and measures 9 subscales, the maximum score in this questionnaire is 348 and the minimum score is 87 . A higher score indicates higher intimacy and a lower score means less intimacy. The alpha coefficient of this test for the questionnaire was reported by its manufacturer (oulia et al., 2006) as 0.92 .

Duel, Dalton, \& Ahmed (2008) designed a set of interventions using a Systemic-Constructivist approach that aims to enhance the couple's understanding of themselves in a marital relationship. In this study, these interventions were performed in 9 sessions for 2 hours.

\section{Results}

The sample for this study included men between 20 and 45 years old and women 26 and 50 years old. Nearly $60 \%$ of the participants had a 5 to 7 -year age
Vol. 20, No. 105, Autumn(December) 2021

difference; $27 \%$ of them, 8 to 10 years, and $13 \%$ more than 10 years. Participants with no children made up $46.66 \%$ of the sample, and members with one or two children accounted for $20 \%$ and $33.33 \%$ of the sample, respectively. The Mean values and Standard Deviation for the pre-test, post-test, and follow-up of the marital satisfaction and intimacy of the couple and all its subscales are shown in Table 1. The results showed that for marital satisfaction the Mean scores of the experimental group increased after the interventions performed in the post-test and followup. This difference was not observed in the control group. The Mean of couple intimacy and all its subscales (except for Physical intimacy \& Religious) increase over time in the experimental group, but the mean values in the control group do not show significant changes (see Table 1). To verify that these increases and decreases are significant, the RepeatedMeasures Analysis of Variance was used (see Table 2). The assumptions for using Repeated Measures Analysis, included the Normal Test, the M-box Test, the Levin Test, and the Sphericity Test were valid. Analysis of the variance showed, there is a significant difference $(p<0.05)$ in all variables of the intimacy of couples and its seven subscales except for religious intimacy and physical intimacy as well as marital satisfaction in the variables of time, group, and interaction of time and group. Therefore, it can be concluded, there is a significant difference in the variables over time, this difference is also significant between the experimental and control groups.

Table 1. Means and Standard Deviations of the Couple Intimacy Subscales

\begin{tabular}{cccccccc}
\hline \multirow{2}{*}{ Variables } & \multirow{2}{*}{ Group } & \multicolumn{2}{c}{ Pre-Test } & \multicolumn{2}{c}{ Post-Test } & \multicolumn{2}{c}{ Follow-Up } \\
\cline { 3 - 7 } & & $\mathrm{M}$ & $\mathrm{SD}$ & $\mathrm{M}$ & $\mathrm{SD}$ & $\mathrm{M}$ & $\mathrm{SD}$ \\
\hline \multirow{2}{*}{ Marital Satisfaction } & experimental & $140 / 05$ & $7 / 53$ & $167 / 40$ & $15 / 24$ & $168 / 90$ & $11 / 86$ \\
& control & $137 / 05$ & 12 & $143 / 70$ & $9 / 57$ & $142 / 70$ & $8 / 71$ \\
& experimental & $31 / 10$ & $5 / 23$ & $39 / 55$ & $3 / 03$ & $40 / 95$ & $1 / 84$ \\
Emotional intimacy & control & $32 / 90$ & $5 / 47$ & $33 / 60$ & $4 / 58$ & $32 / 70$ & $5 / 19$ \\
& experimental & $22 / 55$ & $4 / 25$ & $29 / 70$ & $2 / 41$ & $28 / 95$ & $2 / 23$ \\
Intellectual Intimacy & control & $23 / 10$ & $2 / 71$ & $25 / 50$ & $3 / 12$ & $22 / 70$ & $4 / 35$ \\
& experimental & $17 / 70$ & $3 / 03$ & $18 / 25$ & $3 / 11$ & $18 / 30$ & $3 / 43$ \\
Physical Intimacy & control & $18 / 60$ & $2 / 39$ & $18 / 26$ & $2 / 02$ & $18 / 31$ & $2 / 79$ \\
Social Recreational & experimental & $23 / 05$ & $4 / 81$ & $29 / 55$ & $3 / 05$ & $29 / 20$ & $2 / 69$ \\
Activities Intimacy & control & $23 / 40$ & $2 / 79$ & $25 / 30$ & $3 / 36$ & $23 / 45$ & $4 / 41$ \\
Communication & experimental & $26 / 75$ & $5 / 07$ & $38 / 05$ & $4 / 11$ & $38 / 15$ & $4 / 86$ \\
Intimacy & control & $33 / 50$ & $2 / 52$ & $34 / 75$ & $4 / 14$ & $32 / 35$ & $4 / 08$ \\
Religious, Intimacy & experimental & $25 / 55$ & $2 / 96$ & $26 / 15$ & $2 / 88$ & $27 / 50$ & $2 / 26$ \\
Psychological & control & $26 / 15$ & $3 / 69$ & $29 / 25$ & $4 / 61$ & $25 / 10$ & $5 / 77$ \\
Intimacy & experimental & $25 / 45$ & $6 / 52$ & $34 / 20$ & $2 / 69$ & $33 / 80$ & $25 / 45$ \\
\hline
\end{tabular}


Vol. 20, No. 105, Autumn(December) 2021

\begin{tabular}{cccccccc}
\hline \multirow{2}{*}{ Variables } & \multirow{2}{*}{ Group } & \multicolumn{2}{c}{ Pre-Test } & \multicolumn{2}{c}{ Post-Test } & \multicolumn{2}{c}{ Follow-Up } \\
\cline { 3 - 7 } & & $\mathrm{M}$ & $\mathrm{SD}$ & $\mathrm{M}$ & $\mathrm{SD}$ & $\mathrm{M}$ & SD \\
\hline \multirow{2}{*}{ Sexual Intimacy } & experimental & $22 / 50$ & $3 / 29$ & $23 / 60$ & $5 / 22$ & $24 / 05$ & $4 / 08$ \\
& control & $23 / 25$ & $5 / 68$ & $24 / 75$ & $3 / 68$ & $23 / 10$ & $3 / 61$ \\
General Intimacy & experimental & $39 / 85$ & $4 / 18$ & $51 / 50$ & $5 / 39$ & $52 / 75$ & $7 / 09$ \\
& control & $44 / 80$ & $4 / 94$ & $48 / 10$ & $5 / 70$ & $43 / 61$ & $6 / 32$ \\
\multirow{2}{*}{ Total Couple Intimacy } & experimental & $240 / 95$ & $28 / 09$ & $309 / 05$ & $19 / 58$ & $308 / 30$ & $20 / 17$ \\
& control & $250 / 30$ & $20 / 92$ & $266 / 70$ & $25 / 0$ & $248 / 95$ & $22 / 97$ \\
\hline
\end{tabular}

Table 2. Repeated-Measures Analysis of Variance between subjects and within subjects

\begin{tabular}{|c|c|c|c|c|c|c|}
\hline Variables & source & MS & $\mathrm{F}$ & Sig. & $\mathrm{P}$ & Eta Sq. \\
\hline \multirow{3}{*}{ Emotional intimacy } & Group & $512 / 53$ & $12 / 485$ & $0 / 000$ & $0 / 931$ & $0 / 247$ \\
\hline & time & $295 / 158$ & $33 / 061$ & $0 / 000$ & $1 / 0$ & $0 / 465$ \\
\hline & Group\& time & $277 / 26$ & $31 / 056$ & $0 / 000$ & $1 / 0$ & $0 / 450$ \\
\hline \multirow{3}{*}{ intellectual intimacy } & Group & $326 / 7$ & $15 / 24$ & $0 / 000$ & $1 / 0$ & $0 / 286$ \\
\hline & time & $233 / 01$ & $42 / 301$ & $0 / 000$ & $1 / 0$ & $0 / 527$ \\
\hline & Group\& time & $121 / 67$ & $22 / 089$ & $0 / 000$ & $1 / 0$ & $0 / 368$ \\
\hline \multirow{3}{*}{ Physical intimacy } & Group & $2 / 70$ & $0 / 184$ & $0 / 981$ & $0 / 070$ & $0 / 005$ \\
\hline & time & $0 / 249$ & $0 / 049$ & $0 / 774$ & $0 / 057$ & $0 / 011$ \\
\hline & Group\& time & $2 / 700$ & $0 / 572$ & $0 / 249$ & $0 / 142$. & $0 / 015$ \\
\hline \multirow{3}{*}{$\begin{array}{l}\text { social recreational activities } \\
\text { intimacy }\end{array}$} & Group & $310 / 41$ & $12 / 53$ & $0 / 000$ & $0 / 932$ & $0 / 248$ \\
\hline & time & $189 / 73$ & $26 / 42$ & $0 / 000$ & $1 / 0$ & $0 / 410$ \\
\hline & Group\& time & $101 / 03$ & $14 / 07$ & $0 / 000$ & $0 / 999$ & $0 / 270$ \\
\hline \multirow{3}{*}{$\begin{array}{l}\text { communicational } \\
\text { intimacy }\end{array}$} & Group & $18 / 408$ & $0 / 498$ & $0 / 000$ & $0 / 106$ & $0 / 013$ \\
\hline & time & $446 / 42$ & $55 / 02$ & $0 / 000$ & $1 / 0$ & $0 / 591$ \\
\hline & Group\& time & $441 / 26$ & $54 / 38$ & $0 / 000$ & $1 / 0$ & $0 / 589$ \\
\hline \multirow{3}{*}{ Religious intimacy } & Group & $5 / 633$ & $0 / 188$ & $0 / 762$ & $0 / 071$ & $0 / 005$ \\
\hline & time & $37 / 23$ & $1 / 891$ & $0 / 197$ & $0 / 114$ & $0 / 079$ \\
\hline & Group\& time & $75 / 83$ & $1 / 962$ & $0 / 206$ & $0 / 081$ & $0 / 028$ \\
\hline \multirow{3}{*}{ Psychological intimacy } & Group & $399 / 675$ & $13 / 323$ & $0 / 001$ & $0 / 945$ & $0 / 260$ \\
\hline & time & $511 / 02$ & $41 / 622$ & $0 / 000$ & $1 / 0$ & $0 / 523$ \\
\hline & Group\& time & $236 / 28$ & $19 / 245$ & $0 / 000$ & $0 / 999$ & $0 / 336$ \\
\hline \multirow{3}{*}{ sexual intimacy } & Group & $3 / 008$ & $0 / 065$ & $0 / 001$ & $0 / 057$ & $0 / 002$ \\
\hline & time & $16 / 933$ & $3 / 191$ & $0 / 000$ & $0 / 504$ & $0 / 077$ \\
\hline & Group\& time & $12 / 433$ & $2 / 343$ & $0 / 000$ & $0 / 461$ & $0 / 058$ \\
\hline \multirow{3}{*}{ general intimacy } & Group & $192 / 53$ & $3 / 836$ & $0 / 000$ & $0 / 064$ & $0 / 262$ \\
\hline & time & $618 / 26$ & $32 / 37$ & $0 / 000$ & $1 / 0$ & $0 / 460$ \\
\hline & Group\& time & $502 / 66$ & $26 / 23$ & $0 / 000$ & $1 / 0$ & $0 / 409$ \\
\hline \multirow{3}{*}{ Couple Intimacy total score } & Group & $28428 / 41$ & $24 / 955$ & $0 / 000$ & $0 / 998$ & $0 / 396$ \\
\hline & time & $19730 / 83$ & $88 / 505$ & $0 / 000$ & $1 / 0$ & $0 / 700$ \\
\hline & Group\& time & $12802 / 63$ & $57 / 428$ & $0 / 000$ & $1 / 0$ & $0 / 602$ \\
\hline \multirow{3}{*}{ Marital Satisfaction } & Group & $9100 / 21$ & $43 / 29$ & $0 / 000$ & $1 / 0$ & $0 / 533$ \\
\hline & time & $3763 / 82$ & $55 / 993 ه$ & $0 / 000$ & $1 / 0$ & $0 / 596$ \\
\hline & Group\& time & $1718 / 16$ & $25 / 56$ & $0 / 000$ & $1 / 0$ & $0 / 402$ \\
\hline
\end{tabular}

\section{Conclusion}

The purpose of the present research was to examine The effectiveness of Systemic- Constructivist Couple Therapy (SCCT) on Marital Satisfaction and Intimacy in Older women-younger men marriages in Iran.

Few studies have been conducted on the causes of dissatisfaction of older woman - younger man couples and specifically no educational intervention for these couples was found in the research literature. Studies show that concerns about beauty and appearance, differences in sexual needs, especially at older ages, dissatisfaction with lower incomes of men, power struggles, negative reactions of family and society, recreational needs, and heterogeneous friendship groups are a common concern in these couples (noorani, 2020; Erfanmanesh et al., 2015; Colette et al. 2001; Proulx et al. 2006; Esmaeeli et al. (2019).

Generally speaking, this training program focused on personal, interpersonal, cultural and social concerns of couples in older women - younger men marriages. The results showed that the intervention Couple would cause a significant difference in Couple 
Intimacy and its subscales and Marital Satisfaction for older women-younger men couples in the experimental group in comparison with the control group. These results are consistent with the following studies that show the effectiveness of educationalcounseling interventions on increasing the dimensions of the intimacy and satisfaction of couples; Rajabi, G., naderi, Z., Amanalahi, A., shahni, M. (2015); mami, S., Safarnia, A. (2018); Yousfzadeh, P. farzad, V. Navabinejad, SH. Noorani poor, R. (2017); Fergus, K. D., \& Reid, D. W. (2001). Based on the findings of the present study, it is suggested that the effectiveness of systemicconstructi vist couple therapy on other important dimensions in couples' relationships and different cultural communities be investigated.

\section{Ethical Considerations}

Compliance with ethical guidelines: The authors extracted this article from the $\mathrm{PhD}$ dissertation of the first author, in Family Counseling, Department of Counseling, University of Isfahan, Isfahan, Iran. Ethical considerations like gaining the informed consent of the participants and the confidentiality of responses were considered in this research.

Funding: This study was conducted as a $\mathrm{PhD}$ thesis with no financial support.

Authors' contribution: he first author was the senior author, the second were the supervisors and the third and forth was the advisors.

Conflict of interest: the authors declare no conflict of interest for this study.

Acknowledgments: I would like to appreciate the supervisor, the advisors, the participants. 


\section{اثربخشى زوج درمانى سيستمى - سازهز ا بر صميميت و رضايت زناشويى زوجين داراى سن معكوس}

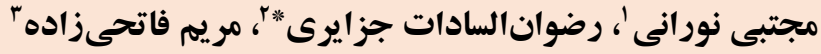

1. دانشجوى دكترى مشاوره خانو اده، دانشگاه اصفهان، اصفهان، ايران.

r. استاديار، گرووه مشاوره، دانشخاه اصفهان، اصفهان، ايران.

r. استاد، گروه مشاوره، دانشخاه اصفهان، اصفهان، ايران.

جكيده

زمينه: مطالعات زيادى درباره رضايت زناشويى و صميميت زوجين صورت گرفته است، اما يُوهشى كه به اثربخشى زوج درمانى سيستى

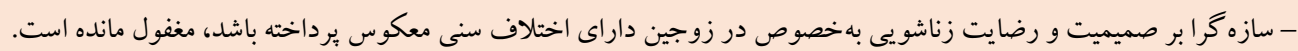

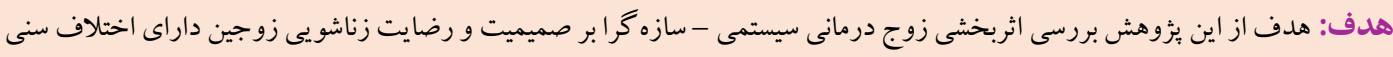

$$
\text { معكوس بود. }
$$

روش: اين بثوهش از نوع شبه آزمايشى با طرح ييش آزمون - بس آزمون و بيخيرى با يك گروه آزمايش و يك گروه گواه بود. جامعه اين

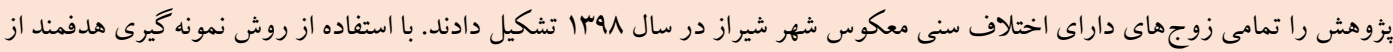

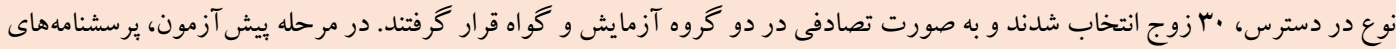

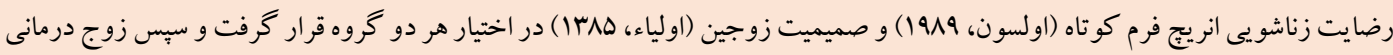

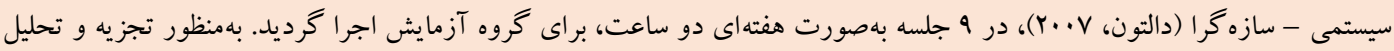

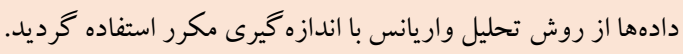
يافته ها: نتايج تجزيه و تحليل دادهها نشان داد كه زوج درمانى سيستمى - سازه گرا بر رضايت زناشويى و ابعاد صميميت هيجانى، عقلانى،

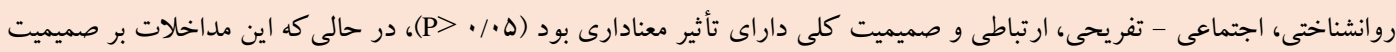
جسمى، معنوى و جنسى تأثير معنادارى نداشته است. نتيجه كيرى: از نتايج به دست آمده مىتوان نتيجه گرفت كه زوج درمانى سيستمى - سازهرًا قابليت اجرا بر زوجين با اختلاف سنى

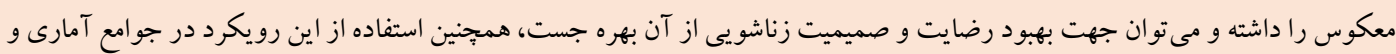

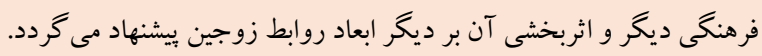

مشخصات مقاله

كليدوازهنا:

زوج درمانى سيستمى - سازهگرا ،(SCCT)

صميميت زوجين، رضايت زناشويى، اختلاف سنى معكوس
دريافت شده: يذيرفته شده: 9./.

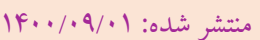

* نويسنده مسئول: رضوانالسادات جزايرى، استاديار، گروه مشاوره، دانشكاه اصفهان، اصفهان، ايران.

r.jazayeri@edu.ui.ac.ir راريانامه: 
ادراكات و تجربههاى زيبايى شناختى همديكر) صميميت زمانى ل (توافقات درباره ميزان وقتى كه زوجين دوست دارند با هم طى كنئد)، صميميت اجتماعى و تفريحى" (انجام فعاليتها و تفريحات مشتر كى).

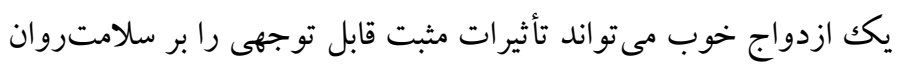

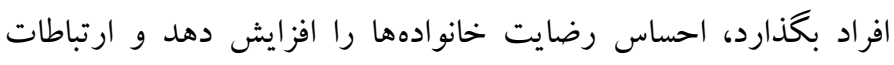

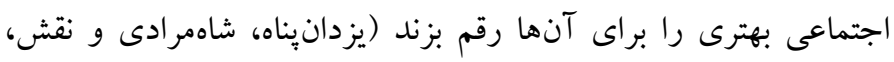

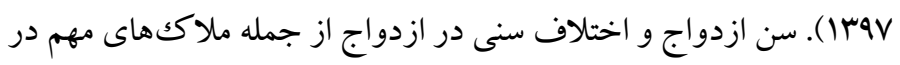

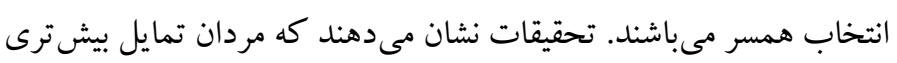

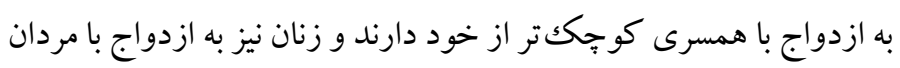

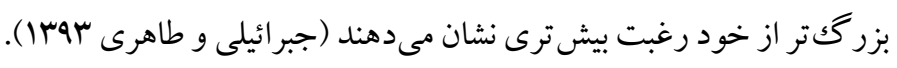

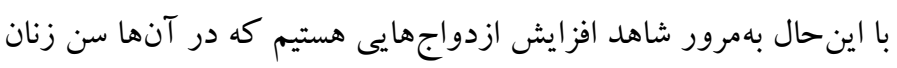

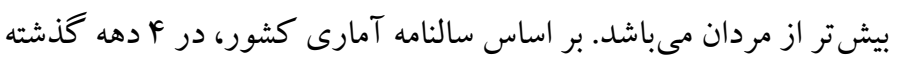

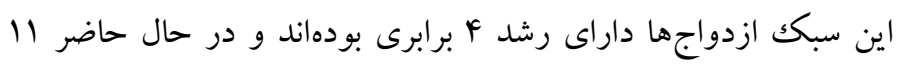
درصد از كل ازدواجها را تشكيل مىدهند (سالنامه آمارى ثبت احوال

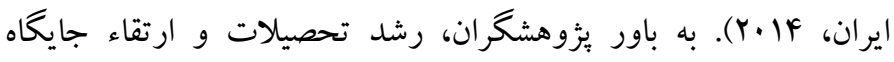
اجتماعى و اقتصادى زنان باعث مىشود كه به نسبت گذشته زنان در سنين بالاترى ازدواج كنند كه اين امر منجر به محدود شدن دايره انتخاب همسر

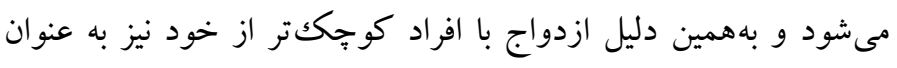

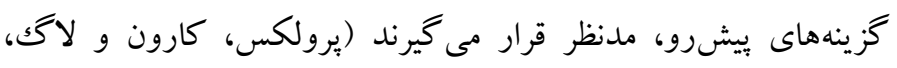

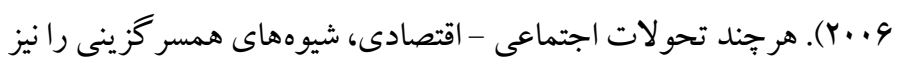

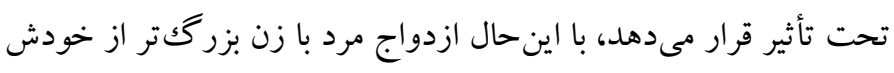

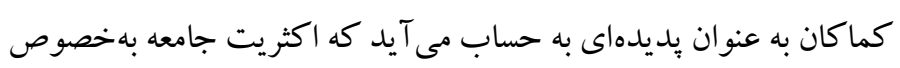

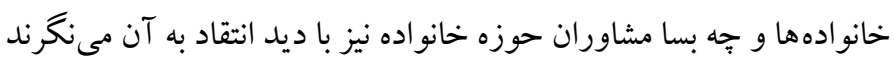

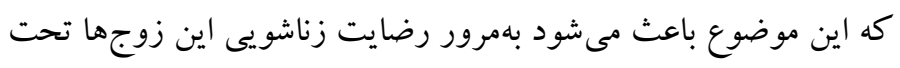

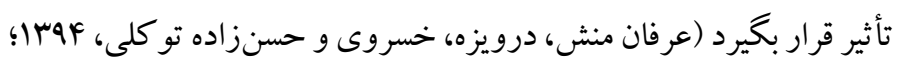

$$
\text { كالت، بانكس و آرنولد، (ب. (Y). }
$$

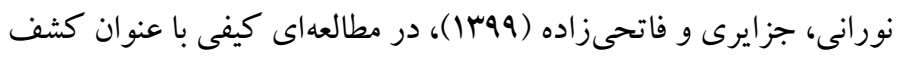

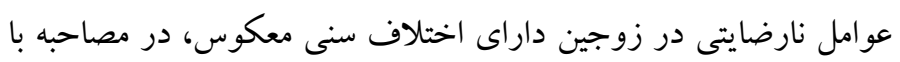

7. Physical

${ }^{8}$. Spiritual

9. Aesthetic

${ }^{10}$. Temporal

11. Social and Recreational
مقالمه

ازدواج يكى از مهم ترين تجربيات زندكى انسان است كه او رادر مسير

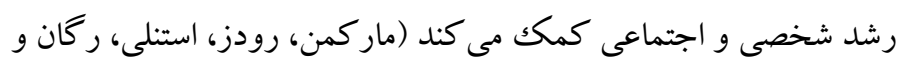

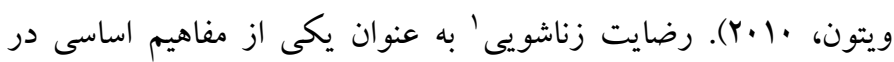

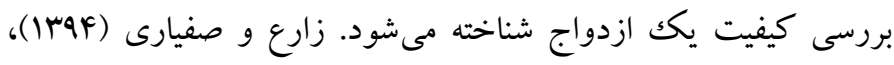
رضايت زناشويى رابه عنوان احساس شادى و خوشبختى زوجين در ازدواج

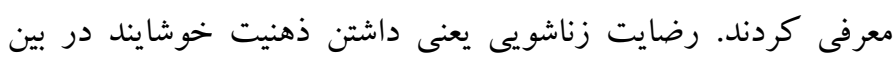

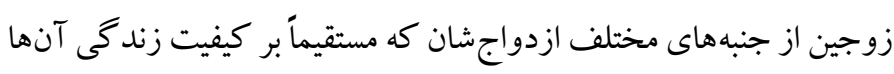

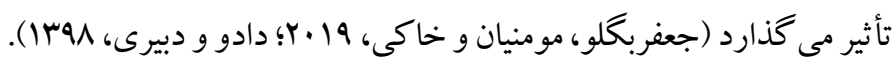
رضايت زناشويى بهعنوان يكى از مهم ترين شاخص هاى تعيين و استحكام

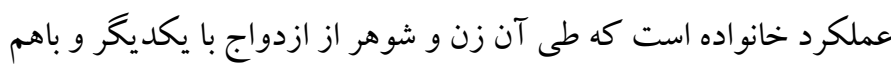
بودن احساس شادمانى و رضايت مى كنند (كارنى و بردبورى، ·r ·r؟ ميرزا

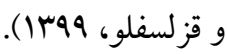

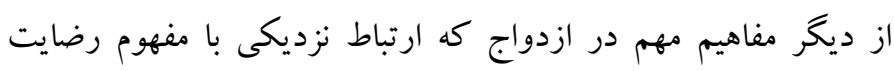

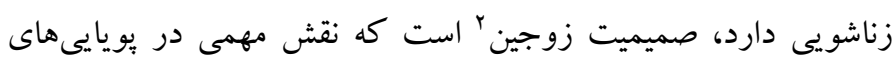
ازدواج و افزايش رضايت زناشويى دارد (كونرى و همكاران، 19 •بr؛ فريرا،

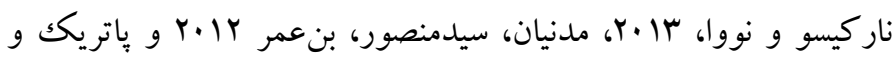

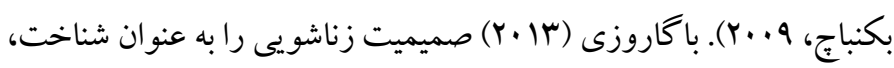
همدلى و درك ديد كاههاى منحصر به فرد ديخرى توصيف كرد و نه مؤلفه را به عنوان ابعاد صميميت زناشويى تعريف كرده است؛ صميميت هيجانى

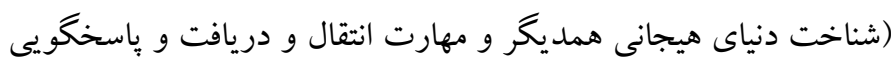

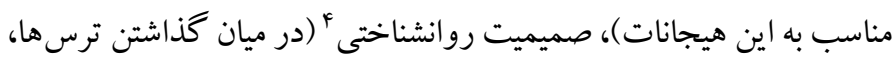

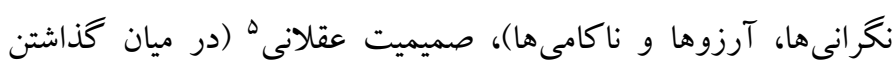

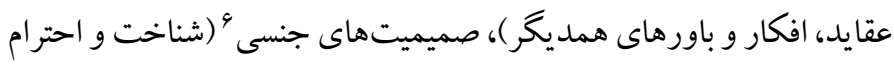

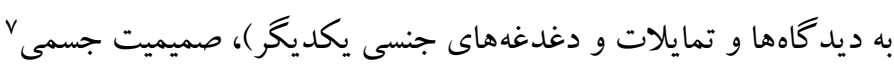

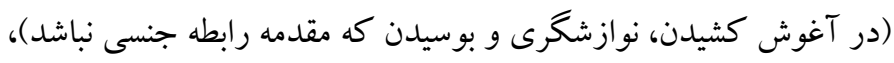

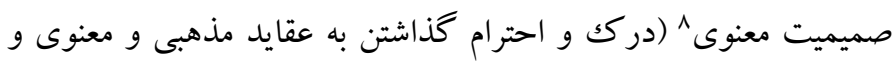

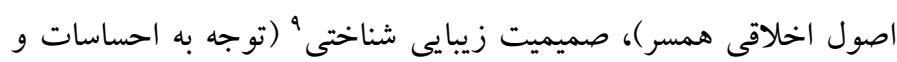

\footnotetext{
1. Marital Satisfaction

2 . Couple Intimacy

${ }^{3}$. Emotional

4. Psychological

5. Rational

6. Sexual
} 
نيازهاى جنسى زن و مرد به سن افراد، در ازدواجهاى سن معكوس

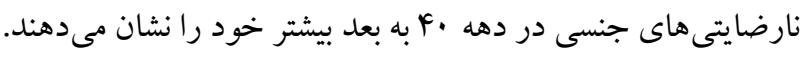

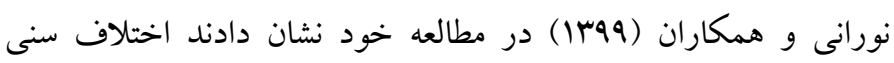
معكوس در برخى از مؤلفها، صميميت را تحت تأثير قرار مى دهد، به ونه

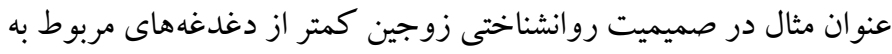

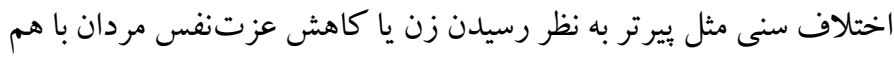

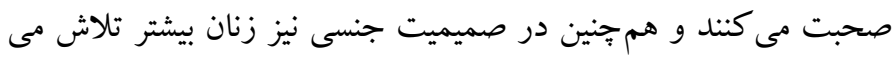

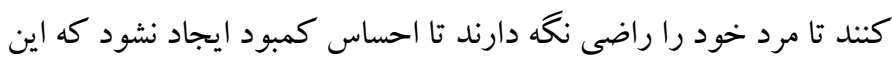

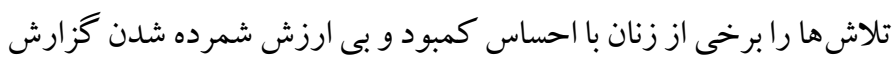
دادهاند. برخى از تحقيقات نيز به بروز مشكلات در صميميت عقلانى در

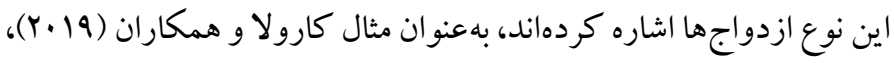

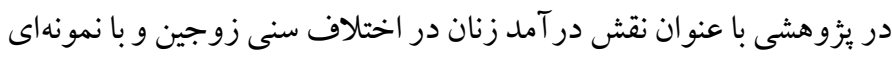

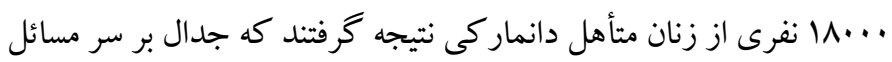

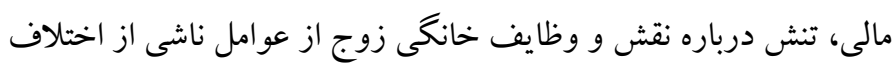

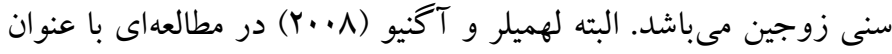

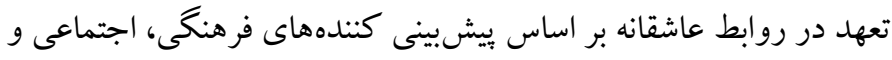

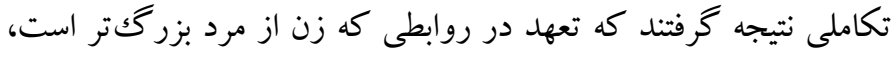

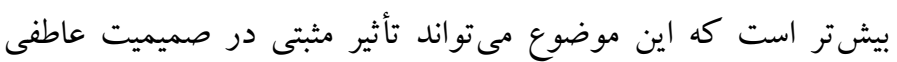
زوجين با اختلاف سنى معكوس بحذارد.

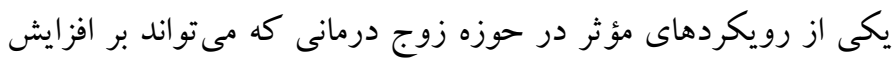

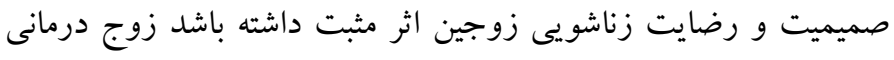

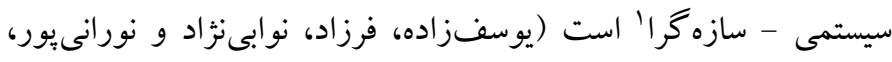

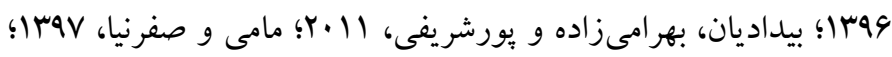

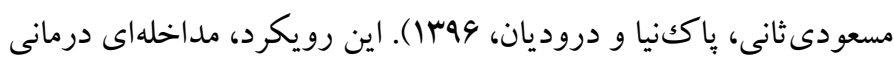

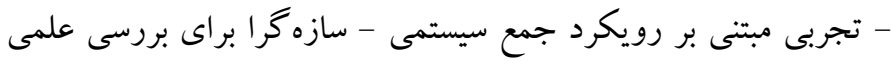

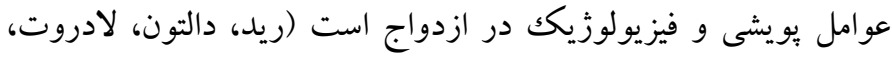

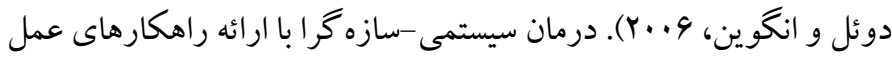

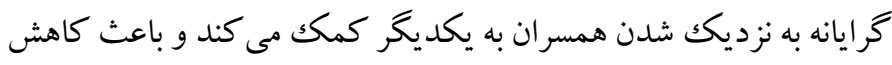

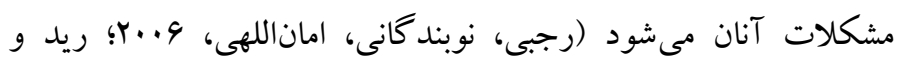

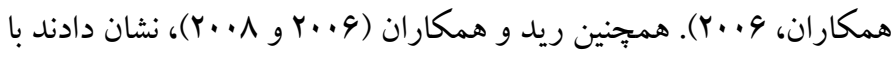

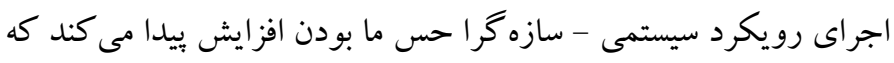

rا زوج كه حداقل ه سال اختلاف سنى معكوس داشتند به برخى از عوامل

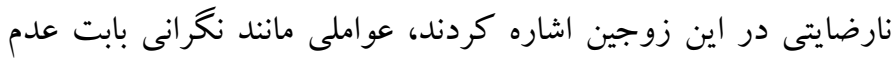

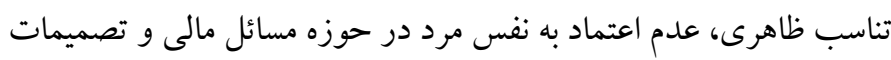

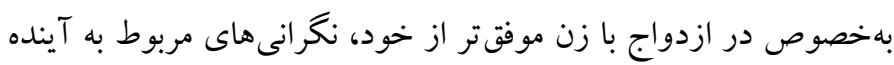
رابطه مثل خيانت كردن، فشار خانو ادهها براى طلاق، عدم حمايت از طرف دوستان و خانو اده كه باعث از دست رفتن احساس امنيت بايدار در رابطه

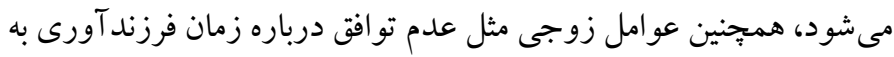

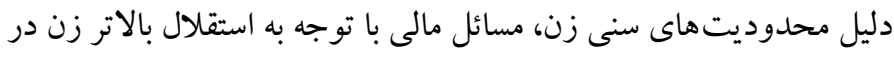
برخى از زوجين و عدم تفاهم در سبك تفريحات با توجه به نيازهاى

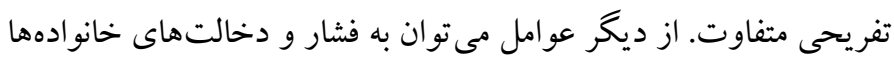
و همجينين زدن برجسبهاى منفى اجتماعى بر ييشانى اين ازدواجها نام برد.

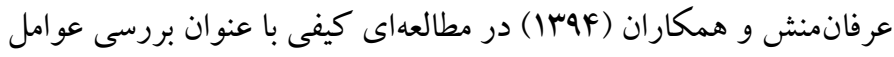
زمينهساز بر كيفيت زناشويى زوجين با اختلاف سنى معكوس در مصاحبه

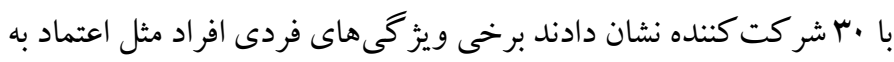
نفس بالا، قدرت متقاعد سازى ديخر ان، حمايت عاطفى از همسر در حضور

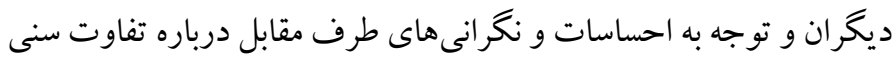
مى تواند به افزايش رضايت زناشويى اين زوجين كمكك كند. اسماعيلى

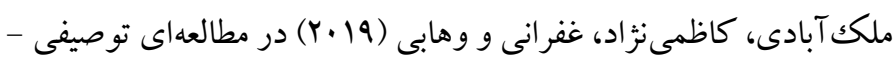

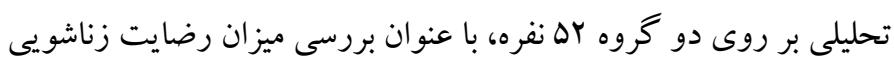

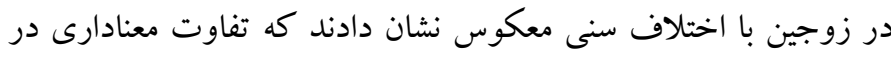
ميزان رضايت زناشويى افراد تا اختلاف سنى معكوس دو سال، با زوجهاى

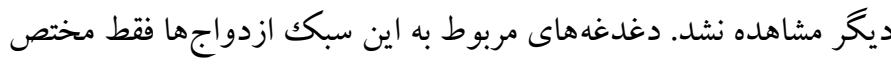

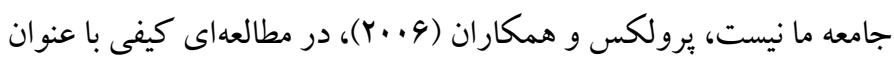

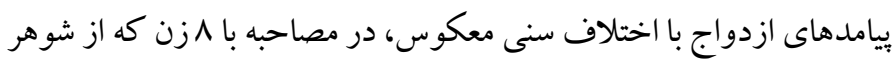

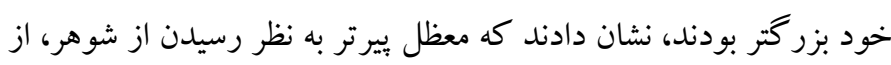
دست دادن تناسب ظاهرى در آينده، عدم توافق در مسائل مالى، نقش و

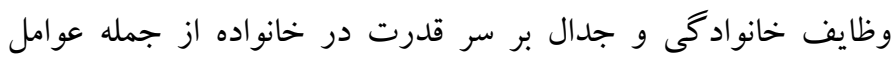

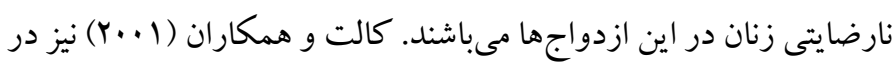
مطالعهاى ييمايشى با عنوان عقايد افراد درباره اختلاف سنى زئ زياد درد

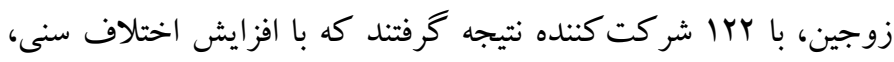

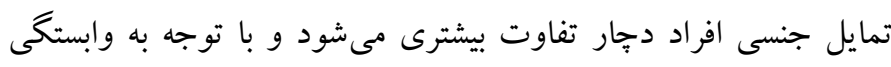

1. Systemic-Constructivist Couple Therapy (SCCT) 
سلامت جسمى و تمايل به شر كت در يزوهش به صورت زوجى و عدم

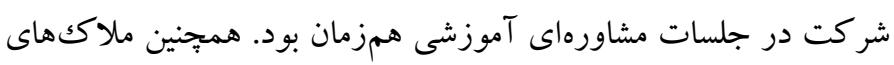

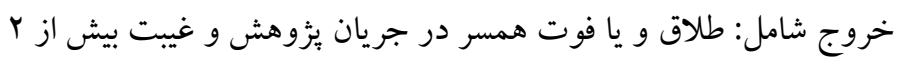
جلسه در نظر گرفته شد.

اصول اخلاقى در بزوهش حاضر شامل اخذ رضر رضايت آكاهانه از

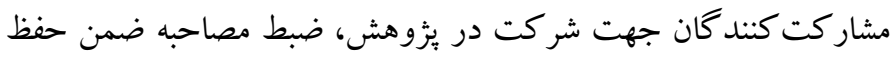

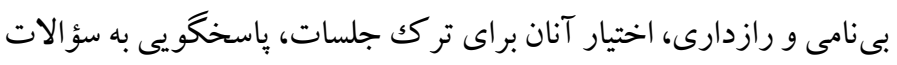

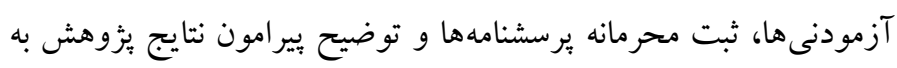

$$
\text { صورت آمارى و كلى بود. }
$$

\section{ب) ب ابز ار}

برسشنامه رضايت زناشويى انريج ': اين مقياس در سال 1919 توسط السون

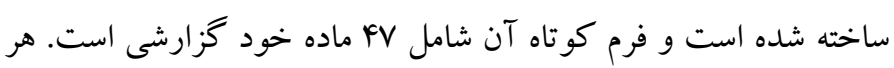

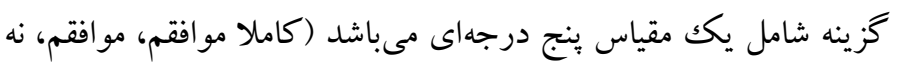

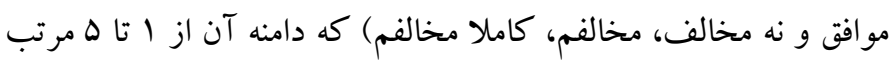

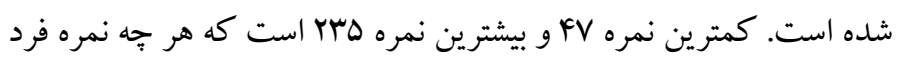

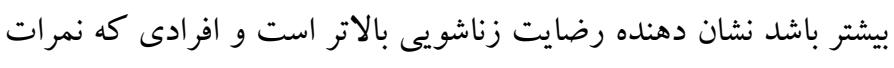

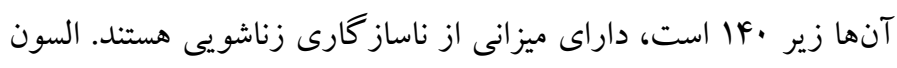
(1919)، ضريب آلفاى كرونباخ را به درصد به به دست آوردد. سليمانيان

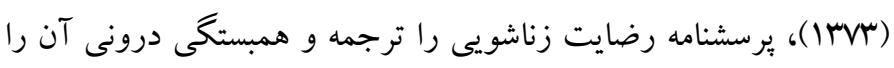

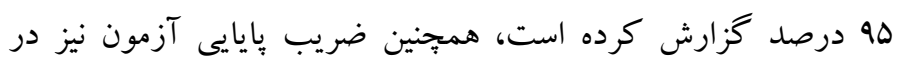

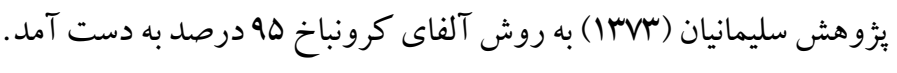

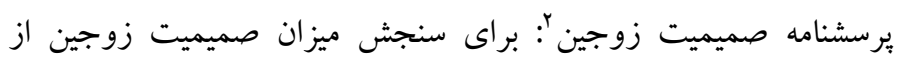

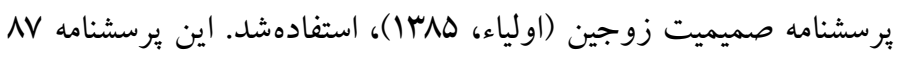

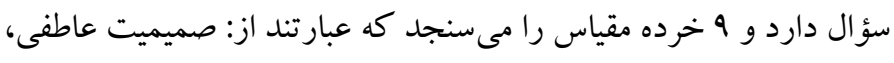
صميميت عقلانى، صميميت بلدى، صميميت اجتماعى - تفريحى، صميميت ارتباطى، صميميت مذهبى، صميميت روانشناختى، صميميت جنسى و صميميت كلى. هر سوال در طيف ليكرت به صورت جهار ززينه

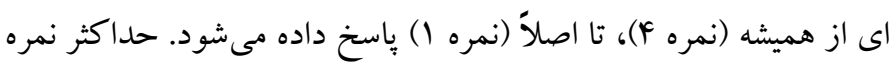

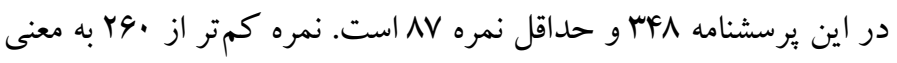

2. Couples Intimacy Questionnaire
اين امر منجر به افزايش يردازش ميانفردى، رضايت زناشويى، رابطه متقابل

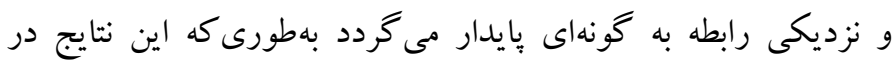
بيخيرى هاى دو سال بعد نيز مشاهده شدهاست.

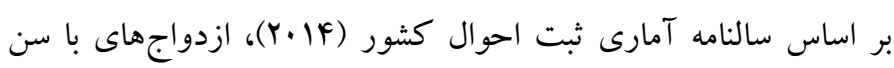

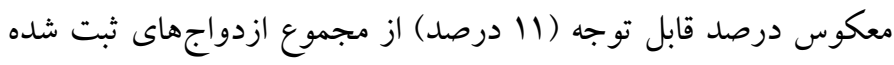

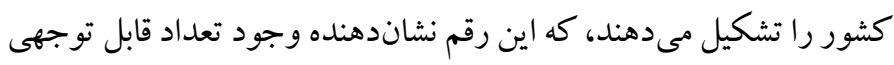

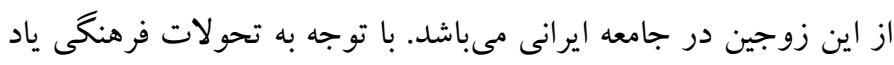

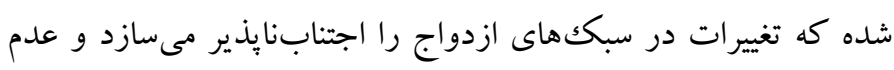
اجراى بسته آموزشى براى اين زوجين، انجام تحقيقاتى منسجم درباره

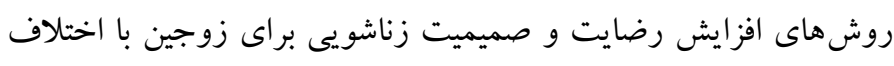

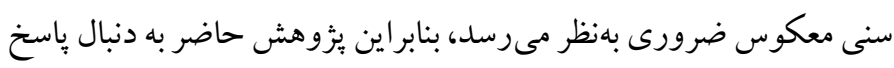

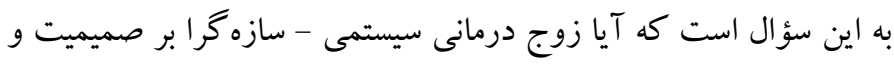

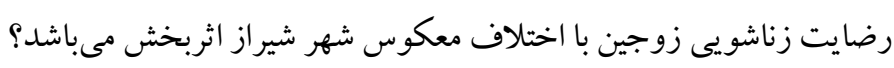

روش الف) طرح :ثؤهش و شركت كنند كان: روش ئزوهش حاضر شبه

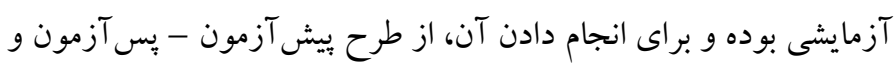

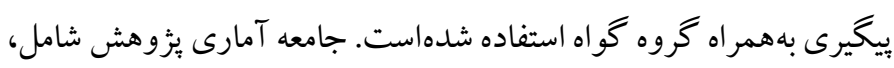

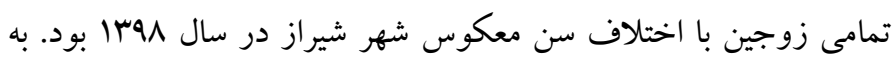

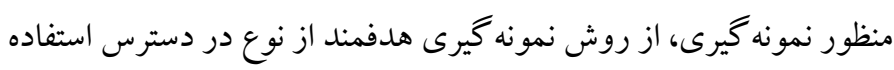
شد، بدين نحو كه با توجه به وجود اطلاعات ثبت ازدواج زوجين شهر لهري

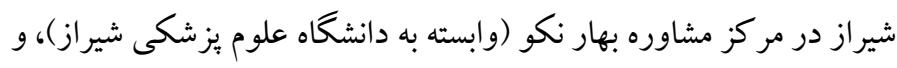
با همكارى اين مؤسسه، با زوجينى كه از نظر اختلاف سنى و مدت ازدو ازدواج

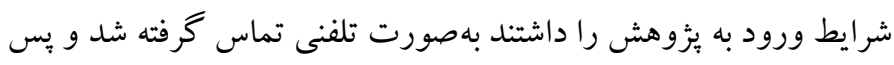

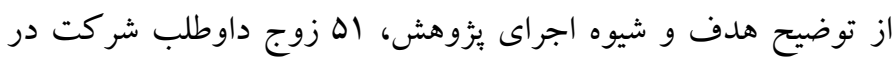

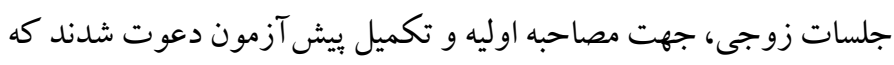

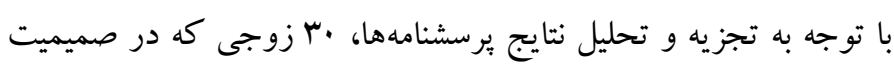

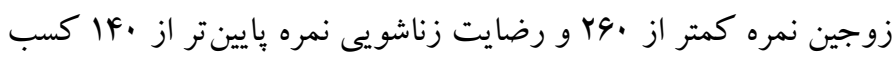

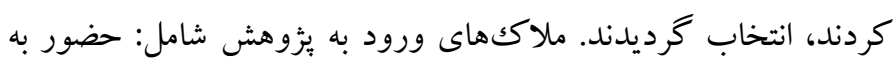

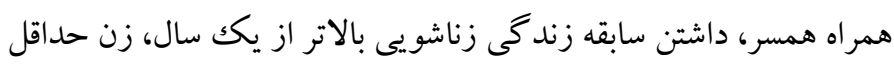

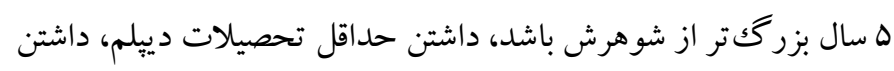

1. Enrich Marital Satisfaction Questionnaire 
هدف آنها تقويت در كك زوج از خود در رابطه زناشويى است، اين درمان به زوجين جهت بردازش اطلاعاتشان از جمله فكر، احساس و هيجان

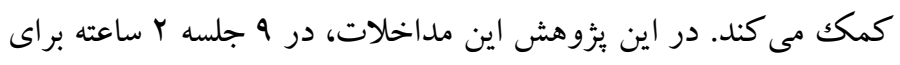
زوجين داراى اختلاف سنى معكوس اجرا گرديد. خلاصه جلسات زورج درمانى سيستمى - سازهگرا در جدول آ آمده است.

يافته ها همانطور كه قبلاً ذكر شد، يُزوهش حاضر به دنبال باسخ به اين سؤال بود

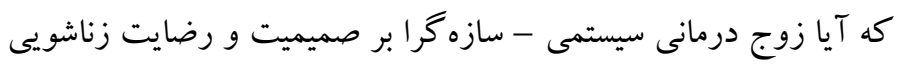

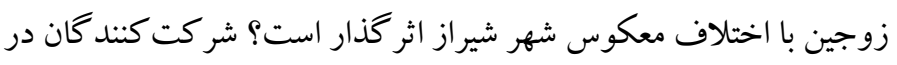

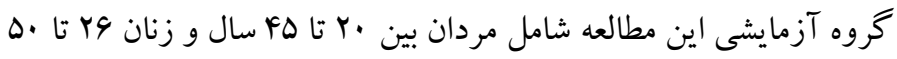

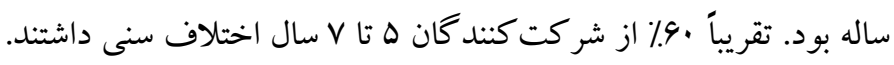

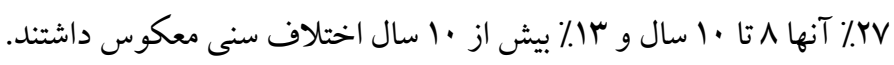

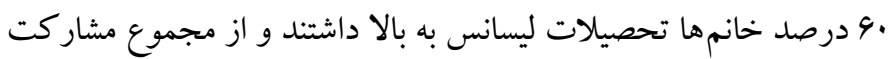

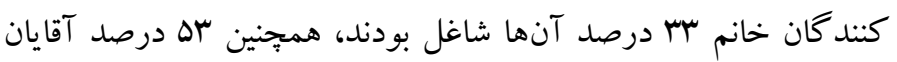
ليسانس به بالا بودند و NV درصد مردان شر كت كننده نيز شاغل بودند.
صميميت زوجى پايين است. ضريب آلفاى اين آزمون براى كل يرسشنامه

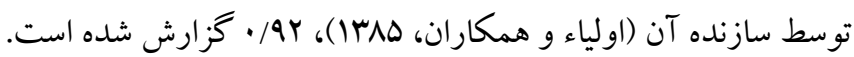

ج) روش اجرا از بين زوجين واجد شرايط، تعداد ·ب زوج انتخاب و به صورت تصادفى

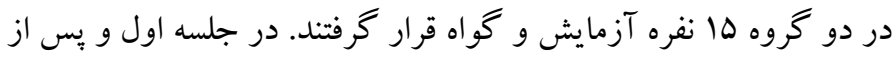

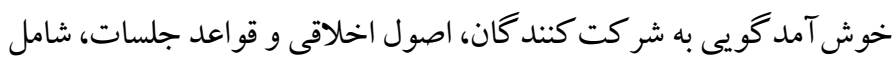
اصل رازدارى، محرمانكى اطلاعات و قواعد حضور در جلسات توضيح داده شد. در طول جلسات بركزار شده، هيج كدام از شركت كنند كان إنان

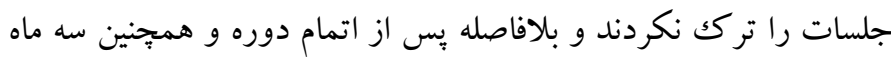

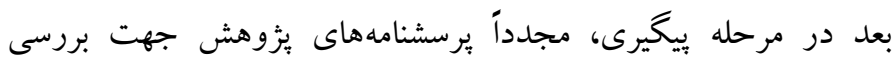

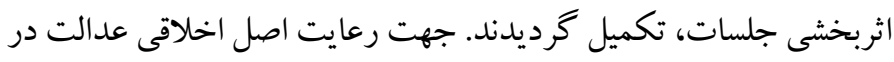
يُزوهش و با توجه به مؤثر بودن جلسات آموزشى و قدردانى از مشاركت

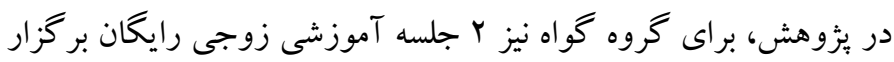
كرديد.

دوئل، دالتون و احمد (1) ㄱ) با بررسى واكنش همسران به درمان بالينى با

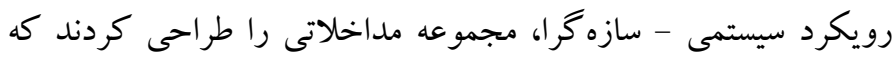

جدول ا. خلاصه محتواى جلسات زوج درمانى سيستمى - سازهزر

\begin{tabular}{|c|c|c|c|}
\hline تكاليف & محتوا & اهداف & عنوان جلسات \\
\hline تهيه ليستى از تعارضات مربوط به اختلاف سنى معكوس & 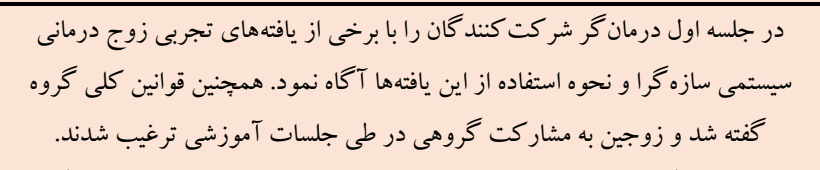 & 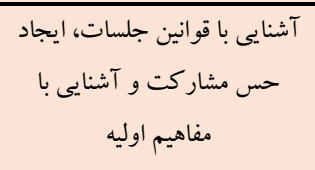 & آشنايى با مفاهيم \\
\hline موراجهه با مشكلات مطرح نشار جديد براى & 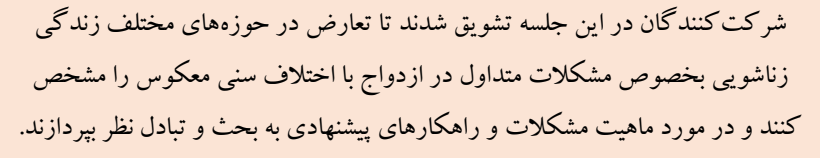 & مختلف و شناخت ماهيت مشكل دروزهلى حوز & ز ز زاشويى تعارضات \\
\hline تمرين فن گوش سيارى & 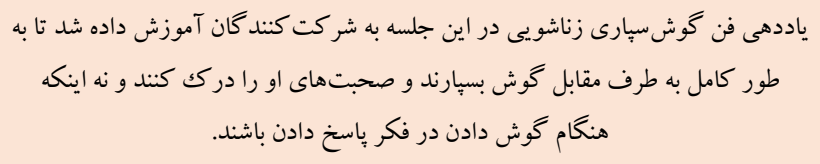 & 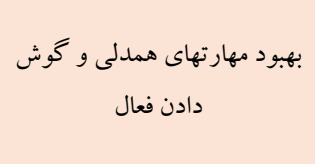 & 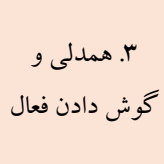 \\
\hline تمرين گفتخوى مؤثر و مشاركت & 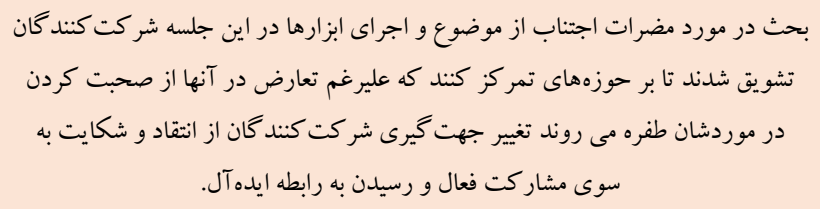 & 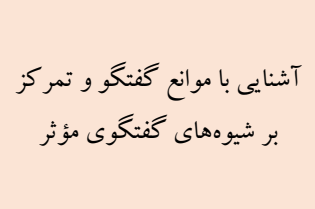 & F ا. كَتخوى مؤثر \\
\hline 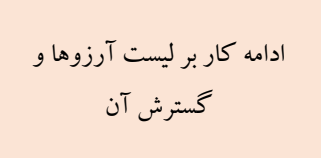 & 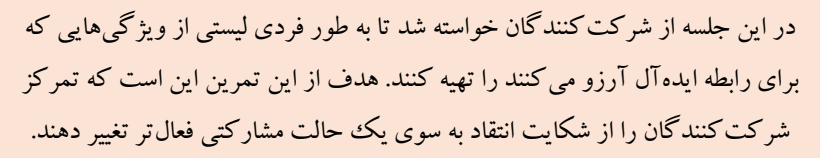 & تغيير شيوههاى كفتخو از انتاد به فعال و بهبود مهارت & هـ ليست آرزوها \\
\hline
\end{tabular}




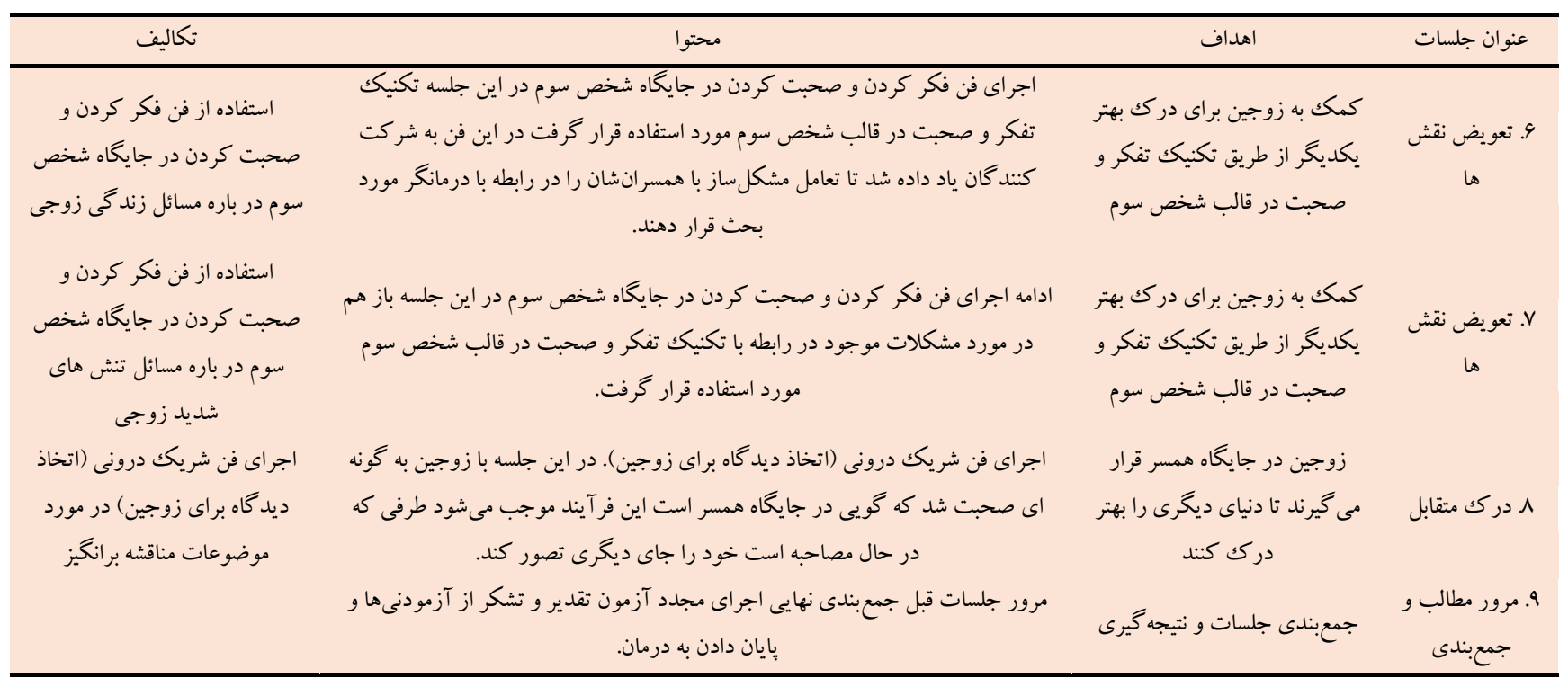

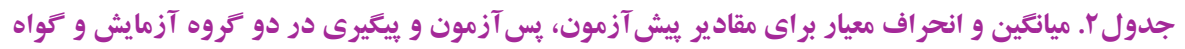

\begin{tabular}{|c|c|c|c|c|c|c|c|}
\hline \multicolumn{2}{|c|}{ ييخيرى } & \multicolumn{2}{|c|}{ يس آزمون } & \multicolumn{2}{|c|}{ ييش آزمون } & \multirow{2}{*}{ كروه } & \multirow{2}{*}{ متغير } \\
\hline انحر اف استاندارد & ميانگين & انحراف استاندارد & ميانگين & انحر اف استاندارد & ميانگين & & \\
\hline $11 / 19$ & $191 / 9$ & $1 D / Y F$ & $19 \mathrm{~V} / \mathrm{F}$. & $\mathrm{V} / \Delta \mathrm{r}$ & $1 F \cdot / \cdot 0$ & آزمايش & \multirow[b]{2}{*}{ رضايت زناشويى } \\
\hline$\Lambda / V I$ & IFY/V. & $Q / \Delta V$ & $1 \mathrm{kr} / \mathrm{V}$. & $9 / 49$ & $\| \pi V / \cdot \Delta$ & كو اه & \\
\hline I/AF & $F \cdot / 90$ & $r / \cdot r$ & $r q / \Delta \Delta$ & $\Delta / r \mu$ & MI/l. & آزمايش & \multirow{2}{*}{ صميميت عاطفى } \\
\hline $8 / 19$ & $r Y / v$. & $F / \Delta \Lambda$ & $\mathrm{rr} / 9$. & $\Delta / F V$ & $M r / q$. & كواه & \\
\hline$r / r r$ & YN/৭D & $r / 4 I$ & $r q / v$. & $r / r \Delta$ & $r Y / \Delta \Delta$ & آزمايش & \multirow{2}{*}{ صميميت عقلانى } \\
\hline f/ro & $r Y / V$. & $r / T r$ & $r \Delta / \Delta$. & $r / V I$ & $r \mu$. & كو اه & \\
\hline$r / F r$ & $1 N / \mu$. & $r / 11$ & WN/TD & $r / \cdot r$ & $\mathrm{IV} / \mathrm{V}$ & آزمايش & \multirow[b]{2}{*}{ صميميت بدنى } \\
\hline$r / V q$ & $|N / \mu|$ & $r / \cdot r$ & $11 / Y 4$ & $r / r q$ & $1 N / 9$. & كواه & \\
\hline$r / 99$ & $r q / r$. & $r / \cdot \Delta$ & $r Q / \Delta \Delta$ & $f / \wedge)$ & $\pi / \cdot \Delta$ & آزمايش & \multirow{2}{*}{ صميميت اجتماعى } \\
\hline$f / F \mid$ & $r M / F D$ & ( & $r \Delta / r$. & $r / V q$ & $r \pi / 4$. & كو اه & \\
\hline F/AG & MN/IO & $F / 11$ & $M N / \cdot \Delta$ & $\Delta / \cdot V$ & rG/VD & آزمايش & \multirow{2}{*}{ صميميت ارتباطى } \\
\hline $4 / \cdot \Lambda$ & Dr/ro & $F / I F$ & $M F / V D$ & $r / \Delta r$ & $\pi / \Delta$. & كو اه & \\
\hline$r / Y G$ & $r V / \Delta$. & $r / M$ & $r 9 / 10$ & r/99 & $r \Delta / \Delta \Delta$ & آزمايش & \multirow{2}{*}{ صميميت معنوى } \\
\hline$\Delta / V V$ & $r \Delta / 1$. & $4 / 91$ & $r Q / r \Delta$ & $r / 99$ & $r 9 / 10$ & كواه & \\
\hline$r \Delta / F \Delta$ & $\mathrm{MT/ \Lambda .}$ & $r / 99$ & $M F / Y$. & G/Dr & $r \Delta / F \Delta$ & آزمايش & \multirow{2}{*}{ صميميت روانشناختى } \\
\hline$r / r \Delta$ & rq/rd & $F / Y q$ & $r 9 / \cdot V$ & $r / \cdot 0$ & $r \Delta / \Delta \Delta$ & كواه & \\
\hline$\varphi / \cdot \wedge$ & $r F / \cdot \Delta$ & $\Delta / Y Y$ & $r r / 9$. & $r / r q$ & $r r / \Delta$. & آزمايش & \multirow{2}{*}{ صميميت جنسى } \\
\hline$r / 91$ & $r \mu /$. & $r / 9 \Lambda$ & TF/VD & $\Delta / 9 \Lambda$ & Tr/ro & كواه & \\
\hline$V / .9$ & $\Delta r / V \Delta$ & $\Delta / / q$ & $\Delta 1 / \Delta$ & $F / \Lambda$ & $\mathrm{rq} / \wedge \Delta$ & آزمايش & \multirow{2}{*}{ صميميت كلى } \\
\hline $9 / \pi T$ & $k r / 91$ & $\Delta / V$ & $F N / 1$. & $F / Q F$ & $F F / \Lambda$. & كو اه & \\
\hline$r \cdot / I V$ & $r \cdot \Lambda / r$. & $19 / 01$ & $r \cdot q / \cdot \Delta$ & $r N / \cdot 9$ & $Y F \cdot / 9 D$ & آزمايش & \multirow{2}{*}{ صميميت زوجين } \\
\hline rY/QV & YFN/৭D & $r \Delta / \cdot$ & r99/V. & $r \cdot / 9 Y$ & $r \Delta \cdot / r$. & كو اه & \\
\hline
\end{tabular}




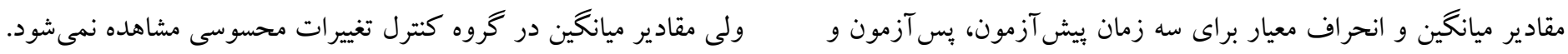

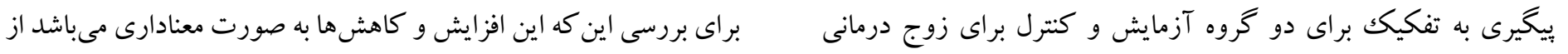

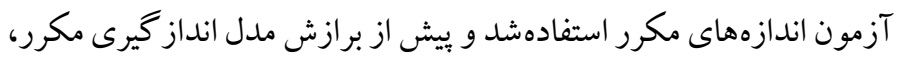

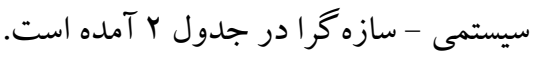
آزمونهاى بيشفرض مورد بررسى قرار خرفتند.

همانطور كه مشخص است رضايت زناشويى، صميميت زوجين و تمام

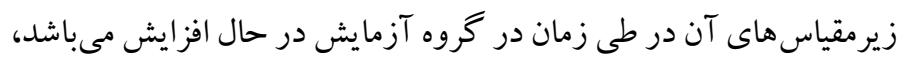

جدول ب. نتايج تحليل واريانس جند متغيرى با اندازهزيرىهاى مكرر براى اثرات بين تروهى و تعامل در نمره كل

\begin{tabular}{|c|c|c|c|c|c|c|c|c|c|}
\hline توان & مجذور & معنادارى سطح & $\begin{array}{c}\text { آزمون } \\
F\end{array}$ & درجه آزادى & درجهآزادى & مقدار & نام آزمون & متغير مستقل & \\
\hline $1 / \cdot$ & $\cdot / \mathrm{WI}$ & $\cdot \%$ & $G Y / F Y V$ & $r v$ & $r$ & $\cdot / \mathrm{VWI}$ & اثرييلاى & زمان & \multirow[b]{2}{*}{ صميميت زوجين } \\
\hline $1 / \cdot$ & $.19 \lambda r$ & $\cdot \cdots$ & rq/arA & rv & r & . /9NR & اثرييلاى & زمان* كروه & \\
\hline $1 / \cdot$ & $\cdot / D F A$ & $\cdot / \cdots$ & $r Y / F \Delta$ & rv & r & $\cdot / D F A$ & اثرييلاى & زمان & \multirow{2}{*}{ صميميت عاطفى } \\
\hline $1 / \cdot$ & - $/ \Delta F \Delta$ & $\cdot \cdots$ & $1 . / 49$ & rv & r & $\cdot / D F \Delta$ & اثرييلاى & زمان* كروه & \\
\hline $1 / \cdot$ & $.199 \mathrm{~V}$ & $\cdot \cdots$ & rG/9AF & rV & r & $.199 \mathrm{~V}$ & اثرييلاى & زمان & \multirow{2}{*}{ صميميت عقلانى } \\
\hline $1 / \cdot$ & - /4af & $\cdot \cdots$ & $11 / \cdot 9$ & rv & r & - / $q q F$ & اثرييلاى & زمانش كروه & \\
\hline$\cdot / \cdot \Delta \Delta$ & $\% r$ & ./99Y &.$/ .4 q$ & $r v$ & r & $\% r$ & اثرويلكز & زمان & \multirow{2}{*}{ صميميت بدنى } \\
\hline$\cdot / 1 Y \Delta$ & $.1 . Y 4$ &.$/ 914$ & $\cdot / 490$ & rv & r &.$/$ rq & اثرويلكز & زمان* گروه & \\
\hline $1 / \cdot$ & .199. & $\cdot / \cdots$ & $F \mid / I$ & rv & r & .199 & اثرييلاى & زمان & \multirow{2}{*}{ صميميت اجتماعى } \\
\hline$\cdot / 99 \mathrm{~V}$ & . &.$/ \cdot 1$ & $9 / r 91$ & rv & r & . & اثرييلاى & زمان* گروه & \\
\hline . /9rA & $\cdot / \mu \cdot$ &.$/ \cdot 1$ & $V / 911$ & $r v$ & r & $\cdot / \mu$ & اثرييلاى & زمان & \multirow{2}{*}{ صميميت ارتباطى } \\
\hline$\cdot / F M$ &.$/$ YF & $\cdot / \cdot \wedge \mathrm{V}$ & r/91Y & rv & r &.$/ M F F$ & اثرييلاى & زمانش گروه & \\
\hline$\cdot / \Delta V G$ &.$/ I F V$ &.$/ \Delta r$ & $r / 19 \vee$ & rv & r & $\cdot / I F V$ & اثرييلاى & زمان & \multirow{2}{*}{ صميميت معنوى } \\
\hline.$/ 119$ & $\cdot / A V F$ & .1949 & . AFr & rv & r & L & اثرييلاى & زماني\% گروه & \\
\hline. $\mid 491$ &.$/ 1 \mathrm{~V}$ &.$/ 11$ & T/FFV & rv & r &.$/ 11 V$ & اثرييلاى & زمان & \multirow{2}{*}{ صميميت روانشناختى } \\
\hline$\cdot / Y \wedge 1$ & $\cdot / \cdot v$ & . / Y & $1 / \pi 91$ & $r v$ & r & $\cdot / \cdot v$ & اثرييلاى & زمان* گروه & \\
\hline ./ITD &.$/ r^{\prime}$ & $\cdot / \Delta V a$ & $\cdot / \Delta \Delta F$ & rv & r &.$/ r q$ & اثرييلاى & زمان & \multirow{2}{*}{ صميميت جنسى } \\
\hline$\cdot / r M A$ & $\cdot / \cdot \Delta r$ & & I/ Fr & rv & r &.$/ \Delta r$ & اثرييلاى & زمان* گروه & \\
\hline . /9rV & $\cdot / / 499$ &.$/ .1$ & V/AVQ & rv & r & $\cdot / 799$ & اثرييلاى & زمان & \multirow{2}{*}{ صميميت زناشويى } \\
\hline . & $\cdot / \cdot \vee \wedge$ & . & $1 / 091$ & rv & r & $\cdot / \cdot \mathrm{vA}$ & اثرييلاى & زمان* گروه & \\
\hline $1 / \cdot$ & .191. & $\cdot / \cdots$ & rN/৭D. & rv & r & .191. & اثرييلاى & زمان & \multirow{2}{*}{ رضايت زناشويى } \\
\hline $1 / \cdot$ & - /DFG & $\cdot / \cdots$ & YY/YFY & rv & r & - /DFG & اثرييلاى & زمان* گروه & \\
\hline
\end{tabular}

همانطور كه در جدول \& مشاهده مى گردد، در تمام متغيرهاى صميميت زوجين و زيرمقياسهاى آن بهجز براى صميميت بلنى، صميميت معنوى و صميميت جنسى، در متغير زمان، گروه و اثر متقابل زمان و گروه تفاوت معنادارى وجود دارد (ه •/ P<). بنابراين مى توان نتيجه كرفت كه علاوه بر اين كه در طى زمان تفاوت معنادارى در متغيرها ايجاد شده است، بين دو كروه آزمايش و گواه نيز اين تفاوت معنادار است.
با توجه به اين كه مقادير سطح معنادارى در آزمونهاى ييش فرض همكى بيش از ه • • • مىباشند، بنابر اين مى توان نتيجه كرفت بيشفرض نرمال بودن

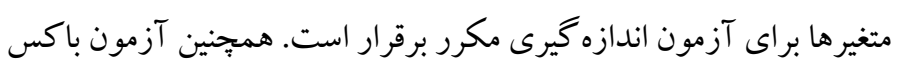
فقط براى صميميت بلنى، صميميت ارتباطى، صميميت جنسى و صميميت كلى برقرار است كه سطح معنادارى آن بيش از هـ / • به دست آمدهاست. براى ديخر متغيرها براى تجزيه و تحليل دادهها، آزمون تحليل واريانس با اندازه گيرى مكرر با عامل درون موردى اندازه گيرى نمره كل در سه دوره دهاي بيش آزمون، يس آزمون و بيگيرى و عامل بين موردى گروه انجام شد. 
جدول ع. نتايج تحليل واريانس بين آزمودنىها و درون آزمودنىها با اندازهتيرىهاى مكرر بر سه بار اندازهتيرى نمره كل در كروههاى آزمايش و كنترل

\begin{tabular}{|c|c|c|c|c|c|c|}
\hline مجذور اتا & توان آمارى & معنادارى & $\mathrm{F}$ & ميانگين مجذورات & منبع تغييرات & متغير \\
\hline I & $1 / \cdot$ & $\cdot / \cdots$ & $k r / Y q$ & $91 \cdots / r 1$ & كروه & رضايت زناشويى \\
\hline$\cdot / \Delta 94$ & $1 / \cdot$ & $\cdot \cdots$ & $\Delta \Delta / ৭ ৭ \Gamma$ & TVGT/AT & زمان & \\
\hline$\cdot / 4 \cdot r$ & $1 / \cdot$ & $\cdot / \cdots$ & $r \Delta / \Delta Q$ & IVIN/19 & زمان و گروه & \\
\hline . IYFV & . & $\% \cdot \cdot 1$ & $\mid r / F \wedge \Delta$ & $\Delta I Y / \Delta T$ & كروه & صميميت عاطفى \\
\hline.$/ 490$ & $1 / \cdot$ & $\cdot / \cdots$ & $\pi / .91$ & $r q \Delta / 1 \Delta \Lambda$ & زمان & \\
\hline.$/ 4 \Delta$ & $1 / \cdot$ & $\cdot / \cdots$ & $\mu_{1 / . \Delta Q}$ & rWV/rG & زمان و گروه & \\
\hline$\cdot /$ / A & $1 / \cdot$ & $\cdot / \cdots$ & $1 Q / Y F$ & MYG/V & كروه & صميميت عقلانى \\
\hline$\cdot / \Delta T V$ & $1 / \cdot$ & $\cdot / \cdots$ & Fr/T.1 & $\mathrm{rm} / \cdot 1$ & زمان & \\
\hline$\cdot / 491$ & $1 / \cdot$ & $\cdot / \cdots$ & $Y Y / \cdot \wedge q$ & $|r| / 9 V$ & زمان و گروه & \\
\hline$\% \Delta$ & $\cdot / \cdot v$ & .1901 & . /MAF & $r / v$. & كروه & صميميت بدنى \\
\hline.$/ .1$ & $\cdot / \cdot \Delta V$ & - /QFF & .1 .49 & - IFFq & زمان & \\
\hline $.1 \cdot 10$ & . / IFY &.$/ 09 \mathrm{~V}$ & $\cdot / \Delta V Y$ & $r / v \cdot$. & زمان و گروه & \\
\hline - /YFA & . &.$/ .1$ & $\mid r / \Delta r$ & $m 1 . / 41$ & گروه & صميميت اجتماعى \\
\hline.$/ 41$ & $1 / \cdot$ & $\cdot \cdots$ & $r g / 4 r$ & $1 \wedge 9 / V r$ & زمان & \\
\hline$\cdot / T V$ &.$/ 999$ & $\cdot / \cdots$ & $\mid F / \cdot V$ & $1 \cdot 1 / . r$ & زمان و گروه & \\
\hline . & .11 .9 & $\cdot / F A D$ & $\cdot / 491$ & $\mid \Lambda / F \cdot \Lambda$ & گروه & صميميت ارتباطى \\
\hline.$/ 091$ & $1 / \cdot$ & $\cdot \cdots$ & $\Delta \Delta / \cdot r$ & FFG/Fr & زمان & \\
\hline$\cdot / \Delta \wedge 9$ & $1 / \cdot$ & $\cdot / \cdots$ & $\Delta F / M \Lambda$ & $F F I / Y q$ & زمان و گروه & \\
\hline$\cdot \cdots \Delta$ & $\cdot / \cdot v 1$ & $.199 \mathrm{~V}$ & $\cdot / M M$ & $\Delta / 9 \pi T$ & گروه & صميميت معنوى \\
\hline$\cdot / \cdot \mathrm{Vq}$ &.$/ 114$ & $\cdot|r|$ & 1/^91 & rV/rT & زمان & \\
\hline.$/ \mathrm{rA}^{\prime}$ & $\cdot / \cdot 11$ & $\cdot / r \cdot r$ & l/99Y & $V \Delta / \wedge r$ & زمان و گروه & \\
\hline.$/ 49$. &.$/ 94 \Delta$ &.$\cdot \cdot 1$ & Tr/r/T & r৭१/৭ V & كروه & صميميت روانشناختى \\
\hline . $/ \Delta r r$ & $1 / \cdot$ & $\cdot \cdots$ & FI/GYY & $\Delta 11 / \cdot r$ & زمان & \\
\hline 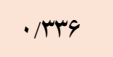 &.$/ 999$ & $\cdot / \cdots$ & $19 / Y F \Delta$ & rMG/rA & زمان و گروه & \\
\hline$\cdot / \cdot r$ & $\cdot / \cdot \Delta V$ & $\cdot / A \cdot 1$ & .1 .90 & $r / \cdots \wedge$ & كروه & صميميت جنسى \\
\hline$\cdot / \cdot \mathrm{VV}$ & $\cdot / 0 \cdot 4$ & .1 .94 & $r / 191$ & 19/9Tा & زمان & \\
\hline$\cdot / \cdot \Delta \Lambda$ &.$/ 491$ & $. / 1 . r$ & r/Mar & Ir/FTr & زمان و گروه & \\
\hline . MGY & .1 .94 & .1 .49 & r/Ars & $19 r / \Delta r$ & كروه & صميميت كلى \\
\hline.$/ 49$. & $1 / \cdot$ &.$\cdots$ & Tr/Tr & $911 / r 9$ & زمان & \\
\hline$\cdot / 4 \cdot q$ & $1 / \cdot$ & $\cdot / \cdots$ & rG/Mr & $0 . r / 94$ & زمان و گروه & \\
\hline . /494 &.$/ 991$ & $\cdot \cdots$ & $r F / 9 \Delta \Delta$ & TAFYN/FI & كروه & صميميت زوجين \\
\hline$\cdot / v \cdot$ & $1 / \cdot$ & $\cdot / \cdots$ & $M / \Delta \cdot \Delta$ & $19 V r \cdot / 1 r$ & زمان & \\
\hline$\cdot 19 \cdot r$ & $1 / \cdot$ & $\cdot / \cdots$ & $\Delta V / F Y \Lambda$ & $\mid r \Lambda \cdot r / 9 r$ & زمان و گروه & \\
\hline
\end{tabular}

وجود ندارد، همجنين در طى زمان و براساس آموزش هاى انجام شده، در اين سه متغير تفاوت معنادارى ايجاد نشده است. براى صميميت ارتباطى نيز بين دو كروه تفاوت معنادارى وجود ندارد ولى در زمان و اثر متقابل زمان و كروه تفاوت معنادارى وجود دارد. بنابراين مىتوان نتيجه گرفت كه آموزش در طى زمان براى هر دو گروه تفاوت ايجاد كردهاست به طورى
با توجه به مقادير ميانگين در جدول ه مىتوان نتيجه گرفت كه، در گروه آزمايش تمام متغيرهاى اين تحقيق در طى زمان افزايشى بودهاند و اين در حالى است كه براى گروه گو اه در طى زمان يا تفاوتى ايجاد نشده است و يا اينكه اين تفاوت معنادار نيست. در مورد صميميت بدنى، صميميت معنوى و صميميت جنسى تفاوت معنادارى بين دو گروه آزمايش و گو اه 
بحث و نتيجه تيرى

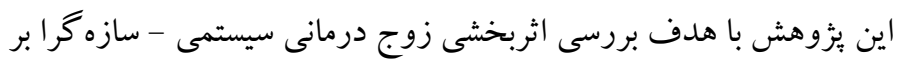

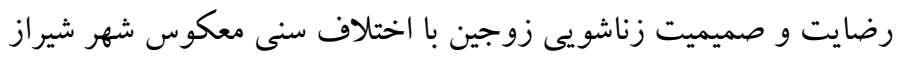

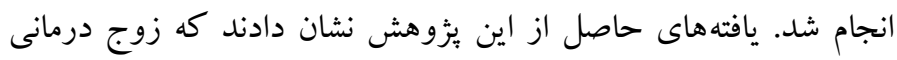

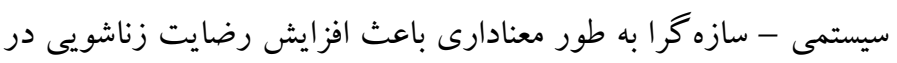
زوجين شدهاست و همجنين ابعاد صميميت عاطفى، عقلانى، ارتباطى، اجتماعى، روانشناختى و صميميت عمومى نيز افزايش مثبى يافته است.

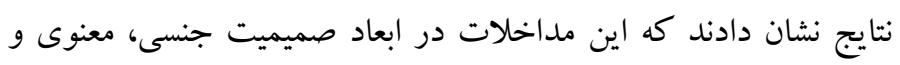
جسمى تأثير معنادارى نداشتند.

در بيشينه بثزوهشى، تحقيقى در زمينه اثربخشى بسته آموزشى براى زوجين با اختلاف سنى معكوس يافت نشد. يافتهاى اين ئزوهش در زمينه

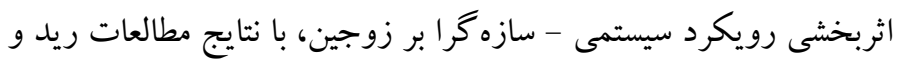

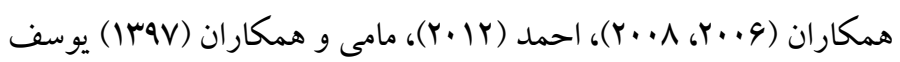

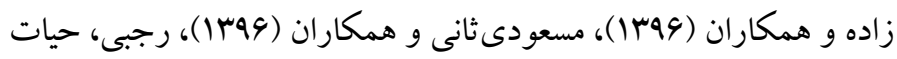
بخش و تقىيور (IrqF) و حسينى و همكاران (IrqV) همسو مىباشندان.

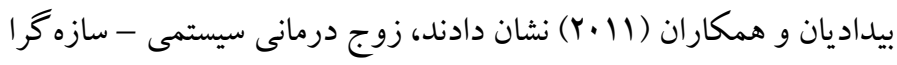
طر حوارههاى ناساز گار را كاهش مىدهد و باعث افزايش ارتباط بين فردى

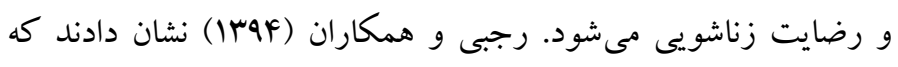

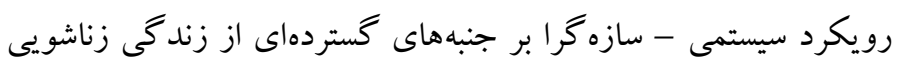
تأثير مى گذارد و دركك زوجين از يكديخر را افزايش مى مدهد. نتايج

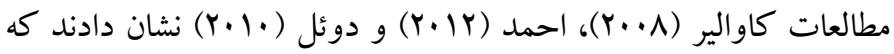
اين درمان مىتواند در افزايش شاخصهاى نزديكى رابطه، صميميت

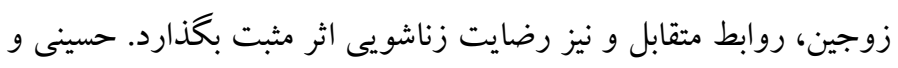

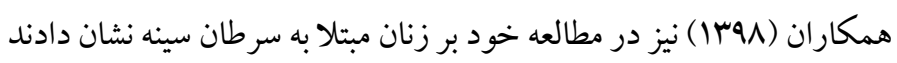

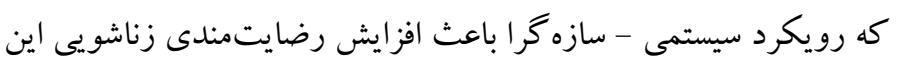
زنان كرديده است.

در تبين كلى نتايج اين يزوهش مئى توان گفت كه، زوج درمانى سيستمى

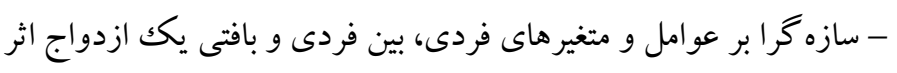

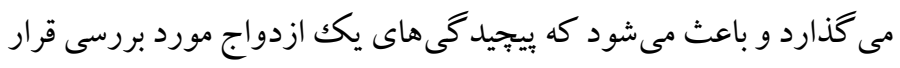

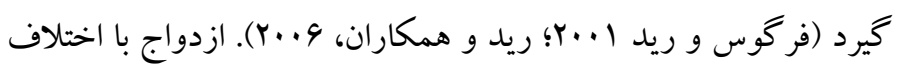

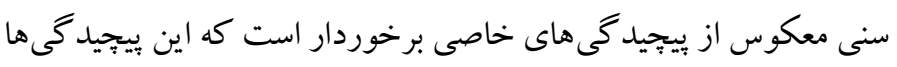

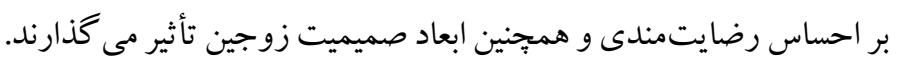

كه بين دو گروه تفاوتى وجود ندارد. با توجه به مقادير ميانگين در جدول

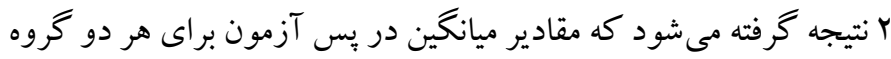

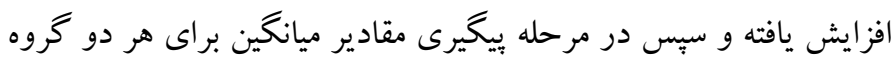
به صورت همزمان كاهش داشتهاست. جدوله. نتايج آزمون تعقيبى بنفرونى براى بررسى سطح زمان

\begin{tabular}{|c|c|c|c|c|}
\hline سطح معنادارى & اختلاف ميانگين ها & \multicolumn{2}{|c|}{ كروه } & \\
\hline$\%$ & $F / \Delta V \Delta$ & يس آزمون & & \\
\hline$\cdot / \cdots$ & F/ATD & بيخيرى & زمون & \\
\hline.$/ 999$ & $\cdot / r \Delta$ & يֶ آزمون & بـ آزمون & روجى \\
\hline$\cdot \cdots$ & F/VVD & ييخيرى & & \\
\hline$\cdot / \cdots$ & $\mu / \cdot$ & يֶ آزمون & زمون & \\
\hline.$/ .1$ & I/VVD & يِيخيرى & يس آزمون & عاطفى \\
\hline.$/ 999$ & $\cdot / 1$ & يُ آزمون & & \\
\hline.$/ 999$ &.$/ 10$ & بيخيرى & & صميميت \\
\hline.$/ 999$ &.$/ . \Delta$ & يس آزمون & يس آزمون & \\
\hline$\cdot / I V I$ & $\cdot / Y 4$. & يِيخيرى & & \\
\hline - rar &.$/ 101$ & يس آزمون & & صميميت بدنى \\
\hline.$/ .81$ & $1 / 1$ & بيشيرى & يس آزمون & \\
\hline$\cdot / \ldots$ & G/TVD & يִ آزمون & & \\
\hline$\% \cdots$ & $\Delta / I T \Delta$ & يِيخيرى & & \\
\hline $.1 .9 \mathrm{~V}$ & $1 / 10$ & يس آزمون & يس آزمون & \\
\hline.$/ 1$ & I/A৯. & ييخيرى & & \\
\hline.$/ 999$ &.$/ 4 \Delta$ & يس آزمون & & \\
\hline (Iro & $1 / \Delta$ & ييخيرى & يس آزمون & \\
\hline.$/ 1.1$ & $1 / 10$ & يس آزمون & $\therefore \cdot T *$ & \\
\hline - MFA & $1 / \mu$. & بيخيرى & تى ارمون & \\
\hline$\cdot / 999$ & $\cdot / 10$ & پِ آزمون & يس آزمون & معتوى \\
\hline .1 .91 & $1 / r$. & ييخيرى & $\therefore$ i & \\
\hline . MYF & $\cdot / v \cdot$ & يس آزمون & لى ازمون & ور صميميت \\
\hline - /afr & $.19 .$. & بي بيخيرى & ״س آزمون & \\
\hline.$/ 914$ & $1 / 4 \cdot 4$ & ֵֶ آزمون & & \\
\hline.$/ 999$ & $1 / \% 99$ & بيخيرى & & \\
\hline$\cdot / 999$ &.$/ 9 Y \Delta$ & يس آزمون & يس آزمون & \\
\hline$\cdot / \cdots$ & TF/IYS & بيخيرى & i) & \\
\hline$\% \cdots$ & $r Y / Q V$ & يس آزمون & كمون & \\
\hline.$/ \cdot 1$ & $11 / 10$ & بي بيخيىى & يس آزمون & زناسويى \\
\hline$\cdot \ldots$ & FY/TD & يس آزمون & $\therefore \cdot T=$ & \\
\hline$\cdot / \cdots$ & $\mu r / .$. & ييخيرى & زمون & رضايت \\
\hline$\cdot / \cdots$ & Q/Y১. & يس آزمون & يس آزمون & \\
\hline
\end{tabular}


زوجى اشتراك نظر ندارند (ريد و همكاران، 9..Y). تفاوت در اختلاف

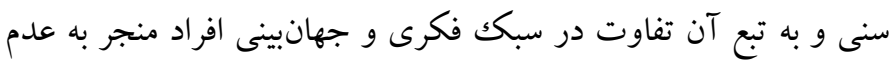

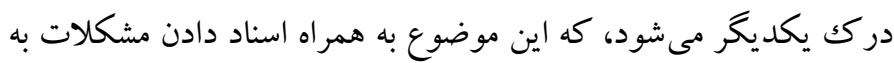

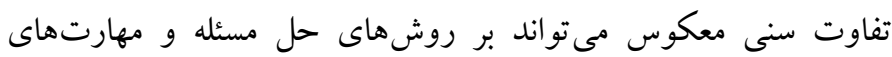

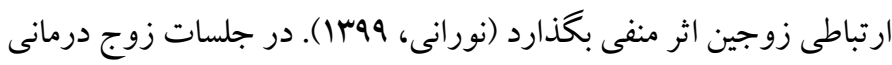

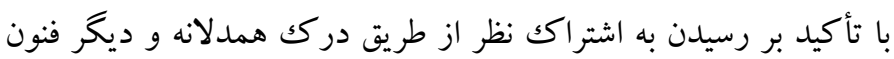

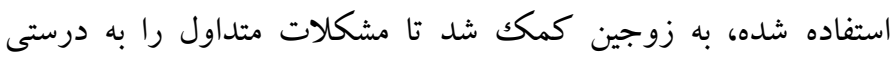

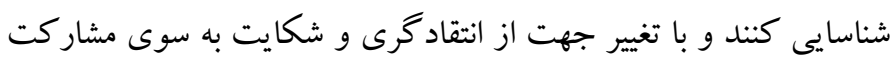

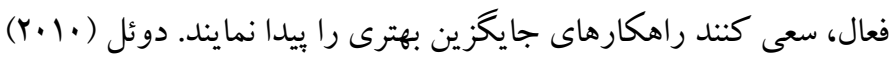
عنوان كرد كه اين رويكرد به زوجين كمكك مى كند كه به تغييراتى اساسى رهاس در مهارتهاى ارتباطى دست بيدا كنند كه اين موضوع باعث بهبود مهارت

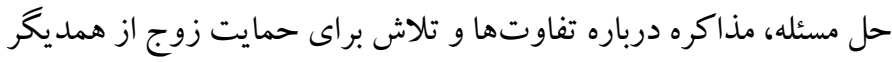

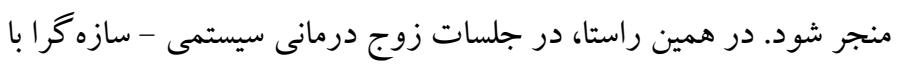

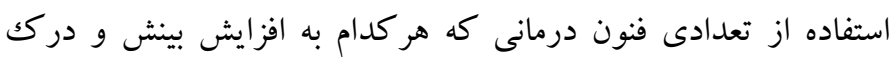

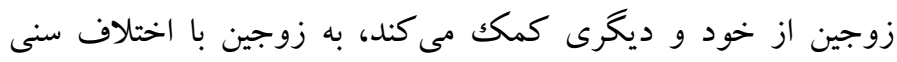

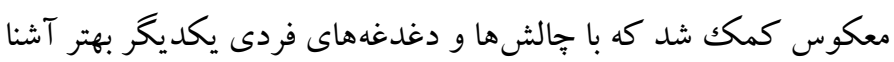

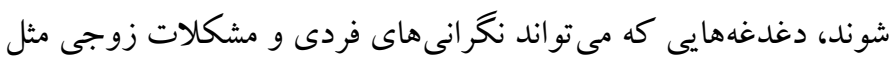

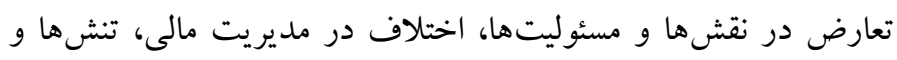

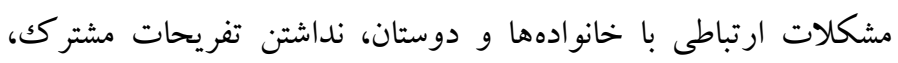
مهارت حل مسئله ضعيف را شامل شود، با توجه به بهبود نمر ات صميميت

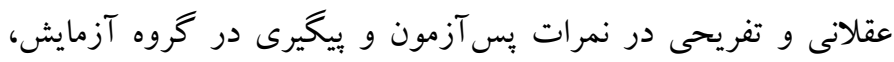

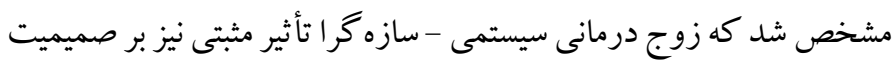
عقلانى و اجتماعى - تفريحى دارد. نتايج نشان دادند، بين نمرات بيش

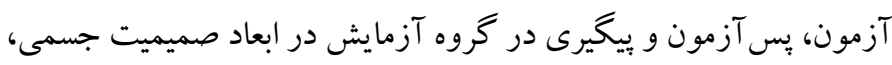
معنوى و جنسى تفاوت معنادارى ايجاد نشده است. در تبيين اين موضوع مى توان عنو ان داشت كه در بعد صميميت جسمى، تفاوتهاى جنسيتى زن و مرد در زبان عشق، مى تواند از جمله دلايل عدم اثربخشى در اين زمينه

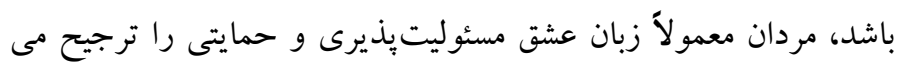

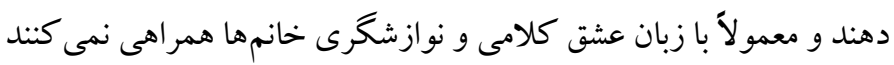

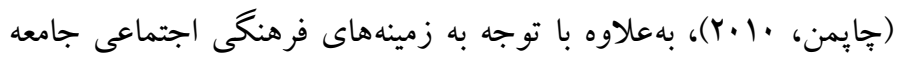

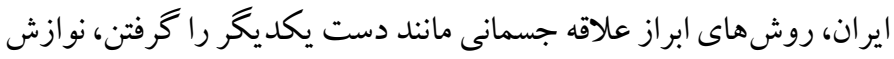

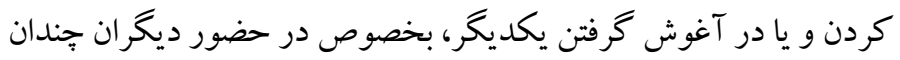

نورانى و همكاران (99 (1)، در تحقيقى با هدف شناسايى عوامل نارضايتى

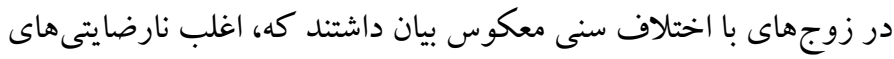

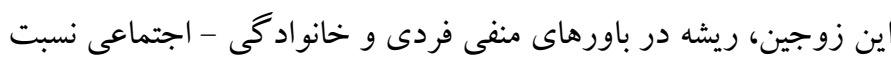

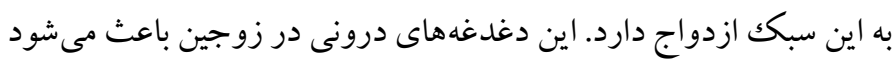
كه احساس ارزشمندى فردى كاهش يابد و به همين دليل، نغر انى هايى مانند

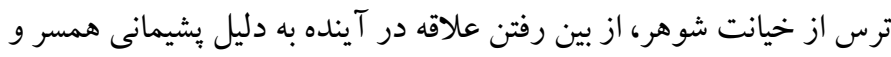
همجنين اضطرابهاى ناشى از عدم تناسب ظاهرى كه مئتواند امنيت

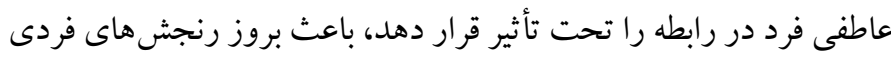
و افزايش نارضايتىهاى زوجى مى شود. مطالعات نشان دادند كه زوج

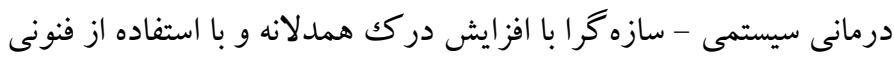

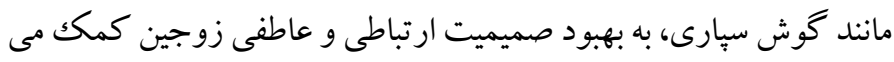

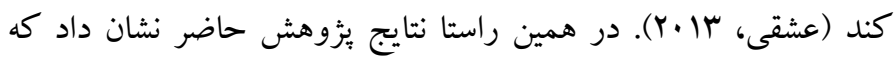

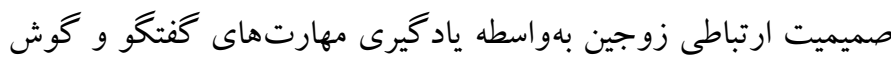

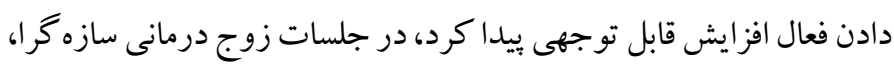

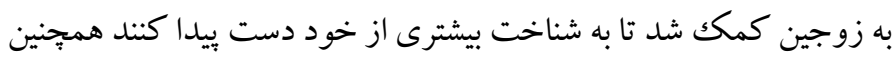
تلاش شد كه زوجين دركك واقع بينانهترى از خود بيدا كرده و مهارت

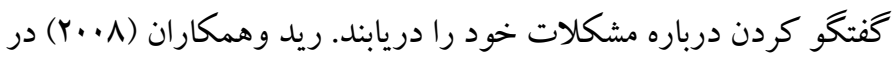

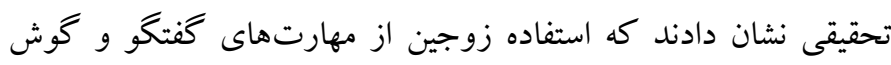

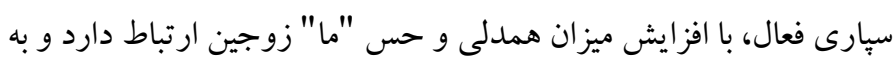

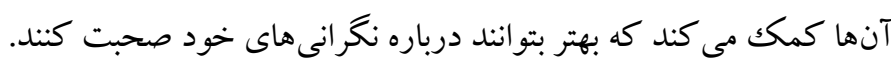
در اين يزوهش با استفاده از اين مهارتها به زوجين با اختلاف سنى هنى

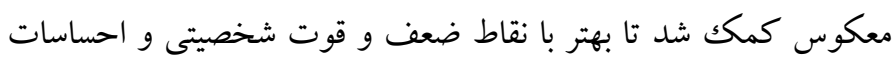

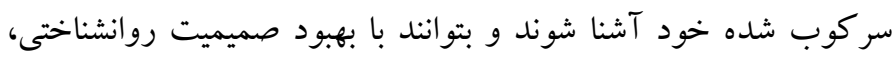
راحت تر از ترسها و نكرانىهاى خود صحبت كنند. همجنين با آثاهى بهتر از احساسات يكديخر و ترغيب شدن به صحبت درباره آنها، صميميت

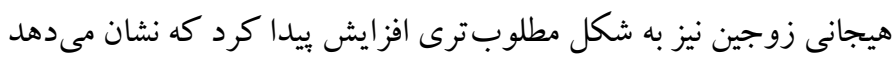
زوجين احساس امنيت روانى بيشترى براى صحبت درباره نغر انى هايشان

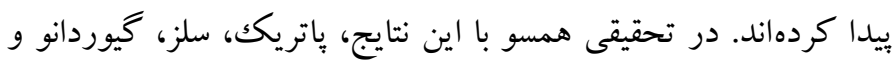

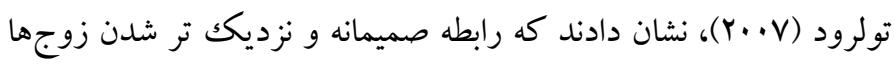

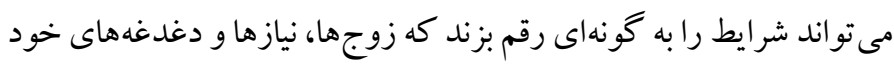

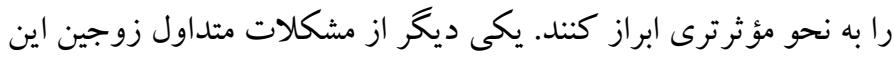

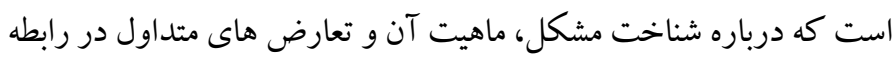


علل نارضايتى و ميزان اختلاف سنى معكوس زوجين اشاره كرد. بر اساس

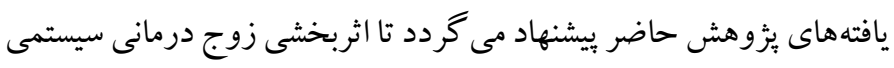

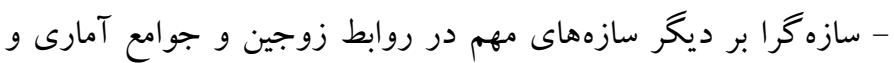

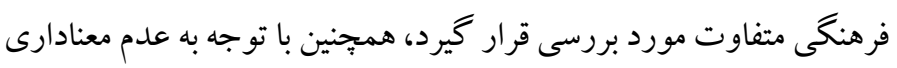
در اثربخشى اين بسته زوج درمانى بر صميميت جسمى، جنسى و معنوى

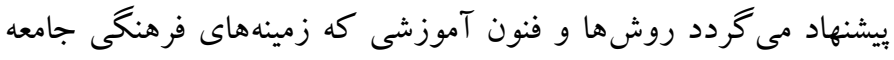

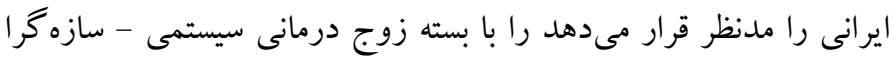

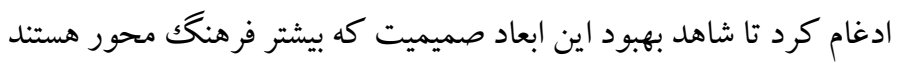

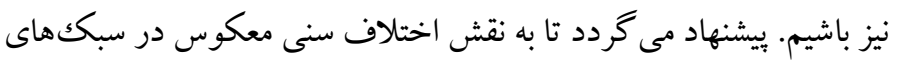
فرزنديرورى زوجين برداختهود و همجنين تفاوت رضايتمندى بين

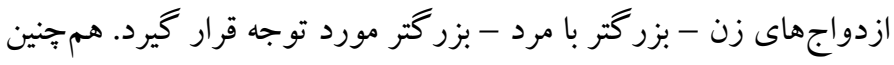

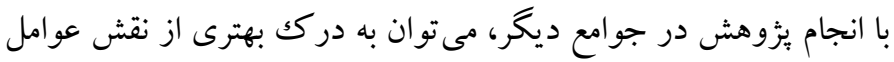

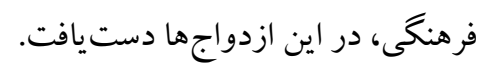

ملاحضات اخلاقى

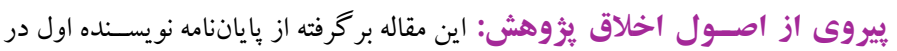

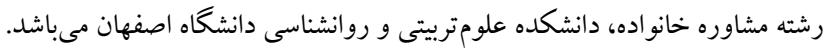

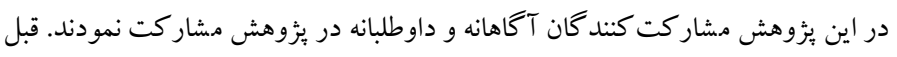

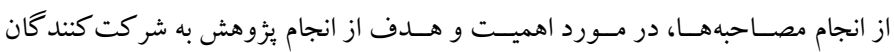
توضـيح داده شـد و بر آزاد بودن براى خروج از يزوهش تأكيد شد. به شركت كنند كان

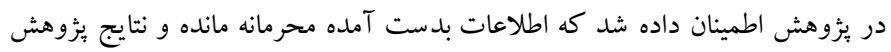
بدون نام و نشان آنها منتشر خواهد شد.

حامى مالى: اين يزوهش در قالب رساله دكترى و بدون حمايت مالى مىباشد. نقش هر يكك از نوي يسندان: نويسنده اول محقق اصلى يثوهش مىبا شد، نويسنده دوم استاد راهنما و نو يسنده سوم استاد مشاوره مىباشند. تضاد منافع: نويسند گان هيج تضاد منافع در رابطه با اين يثوهش اعلام نمىنمايند. زشكر و قدردانى: بدينو سيله از اساتيد راهنما و مشاور محترم و تمامى افرادى كه در به سرانجام رساندن اين يُزوهش يارى رساندند، تشكر و قدردانى مىنمايم.
يسنديده ارزيابى نمىشود و بهنظر مىرسد با مقاوت زوجين بهخصوص مردان در يذيرش آن همراه كشتهاست. صميميت معنوى از ديخر ابعادى بود كه در يثزوهش حاضر بين گروه گواه و گروه آزمايش تفاوت معنادارى ايجاد نشد، يكى از دلايل اين عدم معنادارى مىتواند نبود تفاوتهاى فاحش و تعارضات قابل توجه اعتقادى در بين زوجين باشد، هرجند در جلسات زوج درمانى، درباره مهارتهاى كفتخو كردن و دركك يكديخر، محتوا و تمرينهاى زيادى در اختيار زوجين قرار گرفت، ليكن درباره جزئيات مسائل ارزشى و اعتقادى كه در حريم خصوصى افراد قرار دارد، كمتر مداخله شد. نتايج بزوهش حاضر نشان داد كه صميميت جنسى نيز افزايش معنادارى نداشته است. در تبين اين نتيجه مى توان كفت كه معمولاً بعد صميميت جنسى به دليل باورهاى فرهنكى و شخصيتى افر اد به خصوص در گروههايى كه رضايت زناشويى و صميميت ارتباطى اوليه ضعيفى دارند، جزء مسائلى است كه به سرعت تغيير بيدا نمى كند؛ به بيان ديخر زوجين براى اينكه راحت بتواند درباره نيازها و دغدغههاى جنسىشان صحبت كنتد مىبايست صميميت عاطفى و روانشناختى و ارتباطى خوبى را در رابطه حس كنند و از آنجايى كه زوجين در بدو ورود به مداخلات در تمام اين ابعاد داراى نمرات يائين عدم صميميت بودند، افزايش تدريجى هر كدام از ابعاد صميميت مى تواند در بازه زمانى طولانى تر اثرات خود را در افزايش صميميت جنسى نيز نشان دهند. ضمناً ياد آور مى شود كه در اينجا منظور از صميميت جنسى صرف برقرارى ارتباط جنسى نيست، بلكه فراتر از برقرارى رابطه جنسى، احساس راحتى و شجاعت در صحبت درباره دغدغهها و مشكلات جنسى است كه طبعاً به زمان بيشترى احتياج دارد. از محدوديتهاى يثزوهش حاضر مىتوان به عدم كنترل كامل متغيرهاى مزاحم مانند سابقه ازدواج قبلى، تعداد و نقش فرزندان، تفاوت در مدرك تحصيلى، وضعيت شغلى و مالى، تفاوتهاى فرهنگى - خانوادگى به خصوص درباره نگرشهاى مربوط به اختلاف سنى معكوس، تفاوت در 


\section{References}

Bidadian, M., Bahramizadeh, H., \& Poursharifi, H. (2011). Obesity and quality of life: The role of early maladaptive schemas. Social and Behavioral Sciences Journal, 30 (3), 993 - 998. [LINK]

Carollo, A., Oksuzyan, A., Drefahl, S., Camarda, C., Ahrenfeldt, L., Christensen, K., Van Raalte, A. (2019). Is the age difference between partners related to women's earnings? Demographic Research, 41, 425-460. [LINK]

Colette. A., Banks, C. A., Arnold, P. (2001). Opinions towards sexual partners with a large age difference. Marriage \& Family Review, 33(4), 5-18. [LINK]

Conroy, A.A., McGrath, N., Van Rooyen, H., Hosegood, V., Johnson M.O., \& Fritz, K. (2016). Power and the association with relationship quality in South African couples: Implications for HIV/AIDS interventions. Journal of Social Science \& Medicine, 153, 1-11. [LINK]

Dadoo P, Dabiri S. (2019). Predicting the marital satisfaction based on marital burnout, loneliness and sexual function in married students. Journal of psychological science, 18(76), 499-504. [LINK]

Esmaeeli Malek Abadi F, Kazemnejad A, Ghofrani-pour F, Vahabi N. (2019). The study of marital satisfaction in older woman-younger man marriages. Razi J Med Sci, 26(3), 24-30. [LINK]

Erfanmanesh, N., Darvizeh, Z., Khosravi, Z., \& Hasanzadeh Tvakkoli, M.R. (2015). Qualitative evaluation of predisposing factors in reverse ageheterogamous couples. Journal OF Payesh, 14 (6), 667-675. [LINK]

Fergus, K. D., \& Reid, D. W. (2001). The couple's mutual identity: A systemic constructivist approach to the integration of persons and systems. Journal of Psychotherapy Integration, 11, 385-410. [LINK]

Ferreira, L.C., Narciso, I., \& Nova, R. (2013). Authenticity, work and change: a qualitative study on couple intimacy. Journal of Families Relationships and Societies, 2 \& 3(16), 339. [LINK]

Hoseini Z S, Jahan J, Deihimi M, Sayyah S S, Ranjbar Sudejni, Y, habibi M H Et al. (2019). Compare the Effectiveness of Systemic-Structurally Oriented Couple Therapy and the Teaching of the Pluralistic Family Communication Model on Marital Satisfaction in Women with Breast Cancer. QJCR, 18 (69), 106-132. [LINK]

Jafarbegloo, E., Momenyan, S., \& Khaki, I. (2019). The Relationship Between Sexual Function and Marital
Satisfaction in Postmenopausal Women. Modern Care Journal, 16(1), 1-5. [LINK]

Jebraeili, H., \& Taheri, M. (2014). The role of cultural values in preferences for age of marriage and age difference between spouses. Journal of Iranian Psychologists, 10(40), 421-429. [LINK]

Karney, B. R., \& Bradbury, T. N. (2020). Research on Marital Satisfaction and Stability in the 2010s: Challenging Conventional Wisdom. Journal of Marriage and Family, 82(1), 100-116. [LINK]

Lehmiller, J, J., Agnew, C, R. (2007). Perceived Marginalization and the Prediction of Romantic Relationship Stability. Journal of Marriage and Family, 69 (4), 1036-1049. [LINK]

Mami, S., Safarnia, A. (2018). Efectiveness of SystemicConstructivist Paternity Therapy on the Initial Maladaptive Schemas and Tendency to Extramarital Relationships in the Female Divorce Applicants. Journal of Psychological Studies, 14(1), 75-90. [LINK]

Markman, H. J., Rhoades, G. K., Stanley, S. M., Ragan, E. P., \& Whitton, S. W. (2010). The premarital communication roots of marital distress and divorce: the first five years of marriage. Journal of Family Psychology, 24, 289. [LINK]

Mirza M, Ghezelseflo M. (2020) The effectiveness and sustainability of attributional retraining on marital conflict resolution and increasing marital satisfaction of divorce applicants. Journal of psychological science, 19(88), 482-475. [LINK]

Oulia, N., Fatehizadeh, M., \& Bahrami, F. (2006). The study of effectiveness of instruction marital enrichment on increasing of marital intimacy. Journal of Family Research, 2(6), 119-134. [LINK]

Patrick, S., Sells, J. N. Giordano, F. G. \& Tollerud, T. R. (2007). Intimacy, differentiation, and personality variables as predictors of marital satisfaction. The Family Journal, 15, 359-367. [LINK]

Patrick, Sh., Beckenbach, J. (2009). Male Perceptions of Intimacy: A Qualitative Study. The Journal of Men's Studies, 1(17), 47-56. [LINK]

Proulx, N., Caron, S. L., Logue, M. E. (2006). Older women/younger men: A look at the implications of age difference in marriage. Journal of Couple \& Relationship Therapy, 5(4), 43-64. [LINK]

Rajabi, G., Hayatbakhsh, L., Taghipour, M. (2015). Structural Model of the Relationship between Emotional Skillfulness, Intimacy, Marital Adjustment and Satisfaction. Family Counseling and Psychotherapy, 5(1), 68-92. [LINK] 
Rajabi, G., naderi, Z., Amanalahi, A., shahni, M. (2015). Effectiveness of systemic-constructivistcouple therapy on interpersonal processing and relationship closeness in distressed couples. Psychological Methods and Models, 6(21), 105-128. [LINK]

Reid, D. W., Dalton, J., Laderoute, K., Doell, F., \& Nguyen, T. (2006). The rapeutically induced changes in couple identity: The role of 'we-ness' and interpersonal processing in relationship satisfaction. Genetic. Social and General Psychology Monographs Journal, 132 (3), 121-143. [LINK]

Reid, D. W., Doell, F., Dalton, J., \& Ahmad, S. (2008). Systemic Constructivist Couple Therapy (SCCT): Description of approach, theoretical advances, and published longitudinal evidence. Psychotherapy Theory, Research, Practice, Training, 45 (4), 477490. [LINK]

Yazdanpanah, Y., Shahmoradi, S., Naghsh, Z. (2018). The effectiveness of marital enrichment program on increasing the intimacy and hope of couples with disabled children. Journal of Applied Psychological Research, 8(4), 87-108. [LINK].

Yousfzadeh, P. farzad, V. Navabinejad, SH. Noorani poor, R. (2017). Effectiveness of behavioral-systems couple therapy on psychological wellbeing of maladaptive couples in the city of Tehran. QJCR, 16 (63):50-66. [LINK]

Zare, B., Safyari Jafarabad, H. (2015). The Study of Marital Satisfaction and its Determinants on Married Women and Men in Tehran City. Women's Studies Sociological and Psychological, 13(1), 111140. [LINK] 